\title{
Innovation in pharmaceutical R\&D: mapping the research landscape
}

\author{
Angelo Kenneth S. Romasanta ${ }^{1,2}$ (D) Peter van der Sijde ${ }^{1}$. \\ Jacqueline van Muijlwijk-Koezen ${ }^{2}$
}

Received: 1 November 2018 / Accepted: 2 September 2020 / Published online: 10 October 2020

(c) The Author(s) 2020

\begin{abstract}
In response to the increasing number and breadth of innovation studies on the pharmaceutical industry, we mapped the literature to show the trends in recent research and to indicate areas for further research. In the first phase, we analyzed articles on the pharmaceutical industry published in innovation journals. We used these articles' textual and citation data and applied hybrid cluster analysis. Three main clusters were produced based on the level of analysis innovation scholars had used to investigate the industry: macro, meso and micro. We describe the research topics within these clusters and show that, overall, innovation scholars increasingly focus on the meso-level, analyzing the relationships across different firms. This shift in interest toward the collaborative nature of drug discovery and development was also apparent in macro- and micro-level studies. To explore how this literature is used by scientists in the industry, our second phase involved analysis of the citing articles published in pharmaceutical journals. Using our findings, we propose research areas that can be further explored in order to create an engaged and better-integrated literature on pharmaceutical innovation.
\end{abstract}

Keywords Pharmaceutical industry · Drug development · Innovation · Research and development

\section{Introduction}

Innovation is an important issue for the pharmaceutical industry, especially with regard to bringing new drugs to the market (e.g. Achilladelis and Antonakis 2001; Bianchi et al. 2011). Hundreds of studies on the industry are published each year, exploring the different trends and challenges in innovation in the industry (e.g. Bianchi et al. 2011; Bierly and Chakrabarti 1996; Malerba and Orsenigo 2015; Rafols et al. 2014; Tierney et al. 2013). Despite the increasing number of publications, there have been no efforts to map

Angelo Kenneth S. Romasanta

a.k.s.romasanta@vu.nl

1 Science, Business and Innovation, Vrije Universiteit Amsterdam, Amsterdam, The Netherlands

2 Amsterdam Institute of Molecules, Medicines and Systems (AIMMS), Vrije Universiteit Amsterdam, Amsterdam, The Netherlands 
this literature. Without such overviews, it can be difficult to navigate the wide range of studies published on this industry and thus discern the direction the literature is taking. We therefore mapped the various innovation topics explored in the industry and identified areas for further research. Such a study is an important first step towards a coherent and better-engaged literature on pharmaceutical innovation.

In an earlier synthesis of the wider literature on innovation, Crossan and Apaydin (2010) found innovation to be both a process and an outcome related to the "production or adoption, assimilation, and exploitation of a value-added novelty in economic and social spheres; renewal and enlargement of products, services, and markets; development of new methods of production; and establishment of new management systems." While this is a useful starting point, such a broadly-defined construct overlooks issues that are of greater relevance to specific settings such as the pharmaceutical industry. By exploring innovation within a narrower scope, we hope we can identify the specific issues that matter to practitioners-i.e., scientists and managers in the industry-to help innovation scholars find priority research topics. In addition, as innovation scholars may narrowly focus on specific innovation processes, antecedents and drivers, our study may help show how their individual research fits with the other research carried out on the pharmaceutical industry.

Due to its various unique characteristics, the pharmaceutical industry remains a favored setting for innovation studies. The fast pace of technological advances in the life sciences allows exploration of how firms cope and adapt to change. Leading in research and development (R\&D) investment (Demirel and Mazzucato 2012), the pharmaceutical industry also provides opportunities to study the dynamics between innovation and performance. At the same time, the complexity of drug development means that firms do not have all the capabilities in-house necessary to bringing a drug to the market on their own (Hagedoorn 1993; Powell et al. 2005). Such a dynamic environment enables innovation scholars to observe the flow of knowledge, capabilities, and technologies across different organizations.

The industry is also studied for practical reasons. Despite the variety of therapeutic targets and drug types, the need to ensure safety and treatment efficacy requires the same development cycle to be followed across the industry (Scannell et al. 2012). Such homogeneity makes it relatively easier to compare innovation processes between firms. Another reason is that the process also generates a large footprint of data from various regulatory and intellectual-property protection filings (Cohen et al. 2000). By piecing these together, innovation scholars can gain insight into innovation.

As well as contributing to the innovation literature overall, research on the pharmaceutical industry is important to help the industry address its unique challenges. For many years, the low productivity and return on investment in R\&D have been a central issue for practitioners (Pammolli et al. 2011). At the same time, the cost of bringing a new drug to market has risen continually, the most recent estimate being USD 2.6B (DiMasi et al. 2016). The industry is also subject to increased scrutiny from regulators and the public on the value of different treatments (Scannell et al. 2012). If the innovation literature ensured that it understood the concerns and needs of the industry, its impact for practitioners would be maximized.

While this research is intended mainly for innovation scholars, we hope that our findings will also be of value to scientists and managers in the industry. Even if they are not interested in going into the nuances of innovation theories, they can use the framework we put forward to reflect on the social and economic forces affecting their practice.

We used bibliometric methods to analyze articles on innovation in the pharmaceutical industry. In the following, we detail our methodology, highlighting the hybrid cluster 
analysis we employed based on the combination of citation and textual data provided by the articles. Then, we examine the overall structure and content of the literature in innovation journals on the industry. As a starting point for ways in which the innovation literature might become engaged with issues facing the industry, we explore the diffusion of innovation topics in practitioner journals. We also identify processes in drug development that could benefit from further investigation by innovation scholars. Finally, we introduce creative ways for innovation scholars to gain new insights into innovation theory and the pharmaceutical industry.

\section{Methodology}

To explore both the innovation and practitioner literature, this study consisted of two phases. Data collection and analysis are summarized in Fig. 1. Publication data were collected from the Web of Science in June 2019. Articles on innovation studies on the pharmaceutical industry were collected through a combination of keyword search and journal selection. The keywords "*pharmaceut*", "drug discovery" and "drug development" were used to search for the relevant articles on the pharmaceutical industry.

The main focus of this study is the literature on innovation in pharmaceutical research and development. As many studies of the industry focus on other business functions-such as manufacturing, marketing, finance and sales-we needed to filter out these domain-specific journals. Based on the ranking proposed by Thongpapanl (2012), we therefore narrowed our search to articles in the top-ranked innovation journals: Research Policy, Journal of Product Innovation Management, Research-Technology Management, Technovation, $R \& D$ Management, Industrial and Corporate Change, IEEE Transactions on Engineering Management, Journal of Technology Transfer, Technological Forecasting and Social Change, Journal of Engineering and Technology Management, International Journal of Technology Management, Science and Public Policy, Technology Analysis Strategic Management, Engineering Management Journal and Industry and Innovation.

We also included general management journals that, according to the same paper, were highly cited by the innovation literature. We chose the following: Strategic Management Journal, Management Science, Academy of Management Journal, Academy of Management Review, Organization Science, Journal of Business Venturing, Administrative Science Quarterly, Journal of Management and Journal of Management Studies.

It is important to note that other functions, such as marketing, manufacturing, supply chain and finance, are also key to innovation. These functions inform the R\&D strategy, enabling companies to cope with the pressures from competition, the regulatory burden and increased public scrutiny. Nonetheless, to narrow the scope of this study, we left them aside, as they are vast, thriving and complex research areas that deserve their own analyses.

The initial dataset had 857 articles. The downloaded dataset was rechecked, and articles that lacked the keywords either in the abstract, title or author-selected keywords were removed. We also removed articles that did not have cited references, as these were crucial to our subsequent network analyses. The final dataset, which contained only articles and reviews, consisted of 677 documents. Figure 2 shows the distribution of these articles across journals.

These articles were authored primarily by scholars based in Europe and the United States (see Fig. 3), following that most of the largest pharmaceutical companies are located 


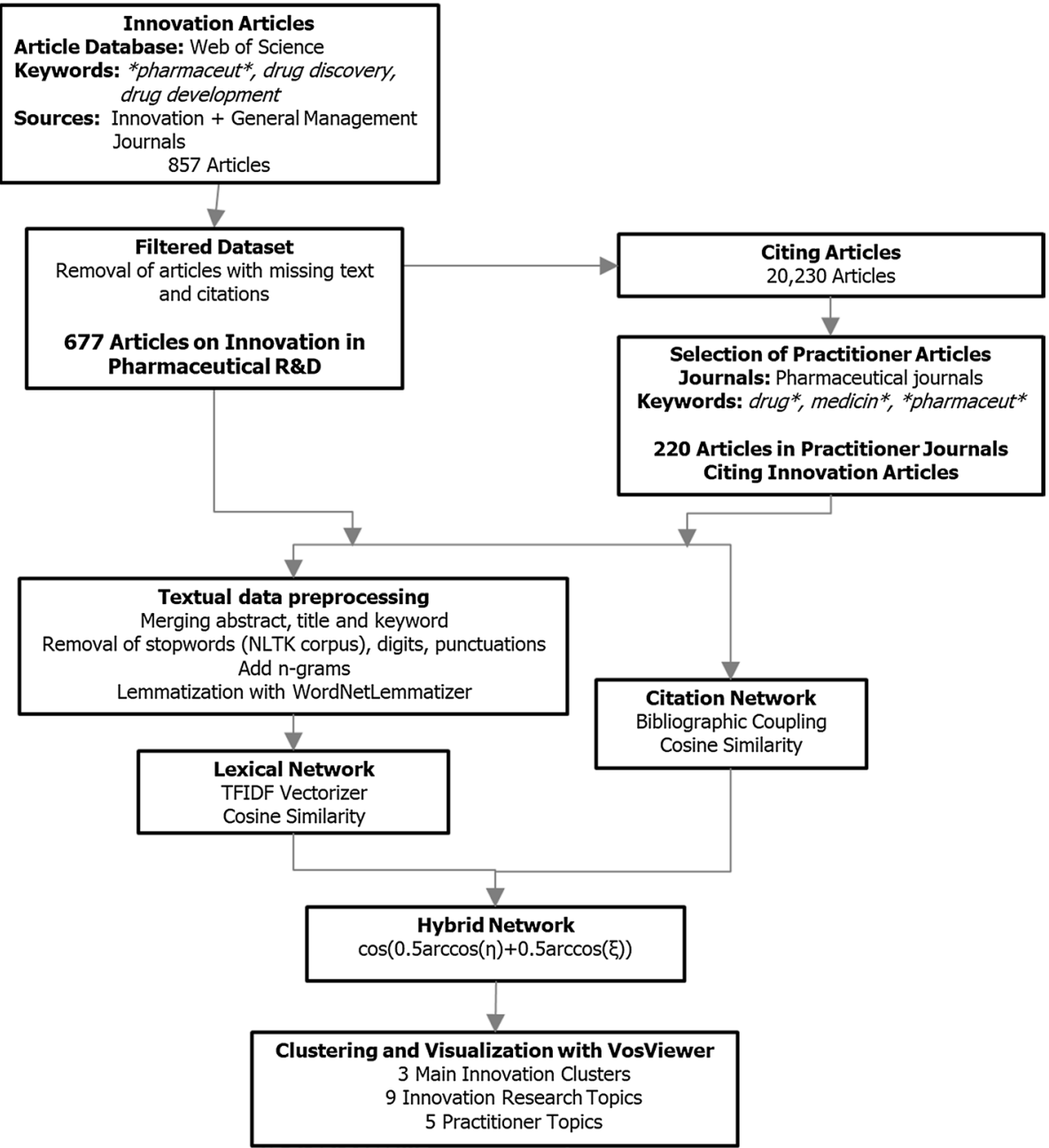

Fig. 1 Data collection and analysis of articles on innovation in the pharmaceutical industry

in these regions. Nonetheless, emerging regions in the industry, such as China and India, are also represented in the dataset.

To analyze the clusters and research topics of the articles, we formed a hybrid network integrating the articles' citation and textual data, following the methodology described by Glänzel and Thijs (2017). First, we constructed the bibliographic coupling network by counting per paper the number of references it shared with each other paper within the dataset. Cosine similarity was then calculated to establish the strength of the bibliographic coupling link between each pair of articles.

Because relying solely on citation data can be limiting - it takes no consideration of textual data, which can also be valuable in establishing relationships between articles-we integrated this information. First, we extracted text from the title, abstract and keywords of each article. This combined text was then preprocessed using the NLTK library in Python (Bird et al. 2009). First, we removed the stopwords (e.g. "I", " $a$ " and "the") in this text. 


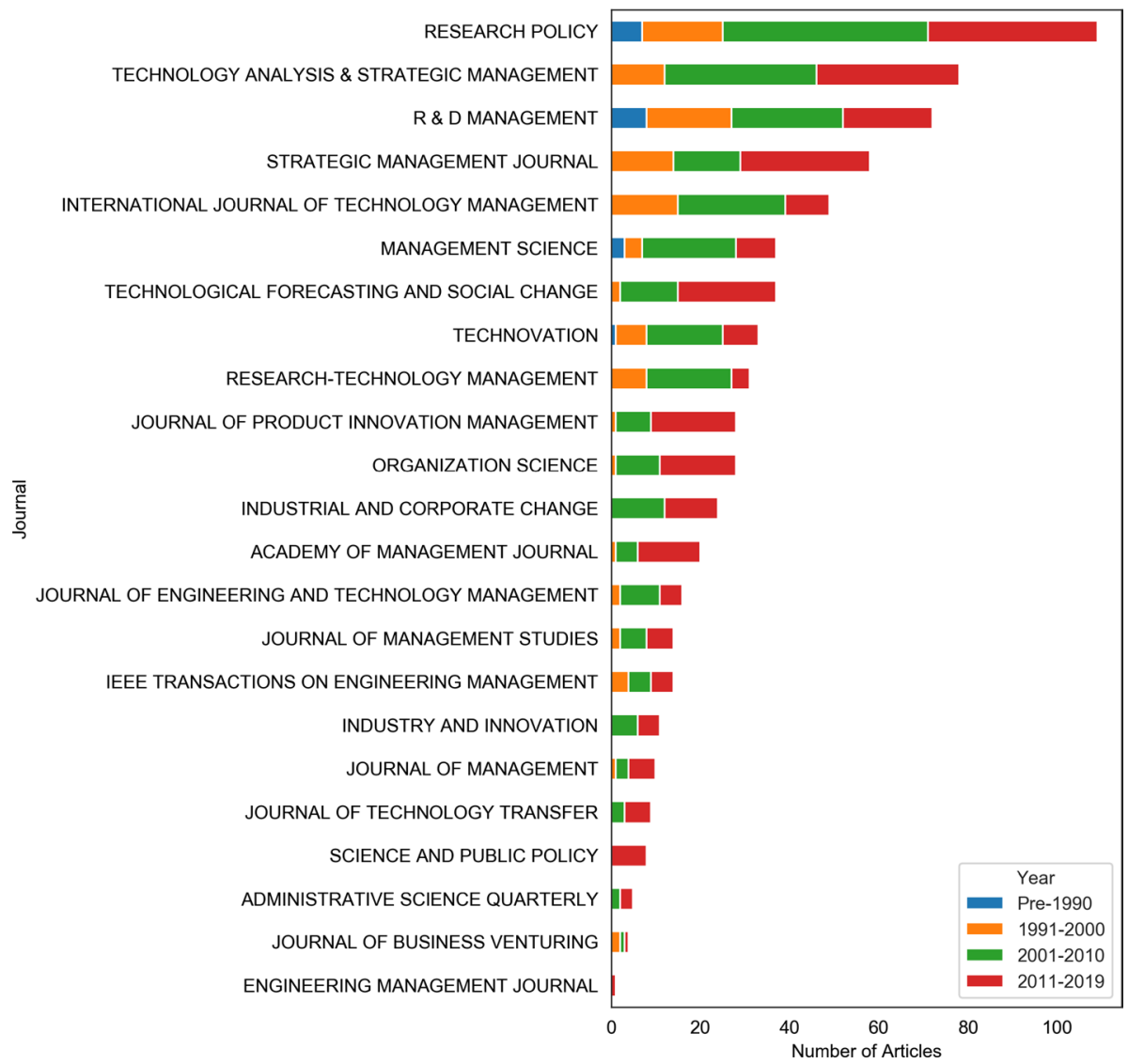

Fig. 2 Articles in the dataset by journal source and year

Punctuation and digits were also removed. We used WordNetLemmatizer in NLTK to reduce different forms of each word to the same lemma. Next, to ensure that terms containing multiple words are analyzed properly (e.g. recognize "absorptive capacity" as one term instead of the words separated), we generated the n-grams in the text to combine words that very often occur in sequence. We combined such terms, setting the threshold that they occur at least 5 times in our dataset. Finally, we selected the terms that occurred most often across all documents and removed those we deemed to add noise to the analysis (e.g. "case," "analyze” and "study").

Once text processing had been completed, we used the Term Frequency Inverse Document Frequency (TF-IDF) vectorizer in NLTK. When TF-IDF is used to weigh each term for each article, less weight is placed on terms that occur very frequently throughout all articles (Ramos 2003). Finally, we calculated the cosine similarity for each pair of documents.

Once the textual and citation relationship between each paper had thus been measured, we combined these measures to create a hybrid network. Following Glänzel and Thijs (2017), we took the cosine of the linear combination of the underlying angles between the vectors representing the documents in the original networks. To calculate the similarity 


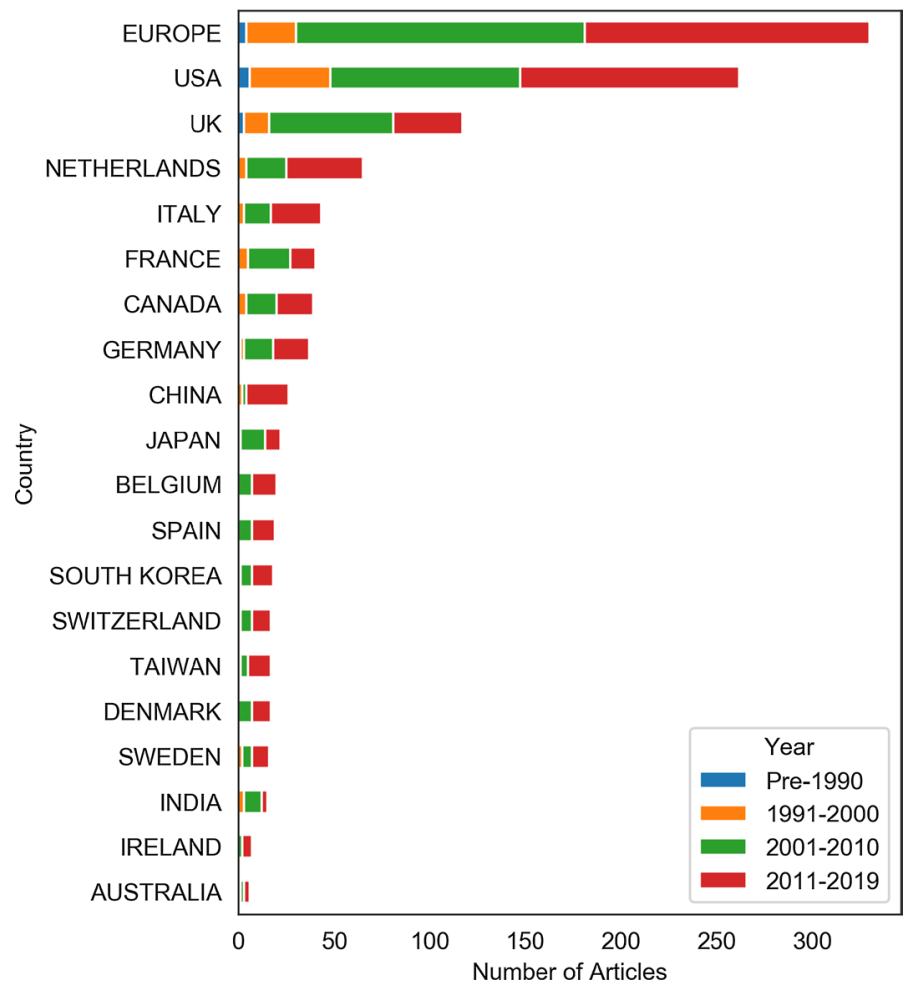

Fig. 3 Articles in the dataset by authors' country affiliations and by year

score $r$, we gave the equal weight of 0.5 to both the textual network $(\xi)$ and the citation network $(\eta)$ using the formula:

$$
r=\cos (0.5 \arccos (\eta)+0.5 \arccos (\xi))
$$

This value $r$ was used as the link strength for each pair of articles, which was then imported to VosViewer for clustering and visualization (van Eck and Waltman 2010). Except for the visualization and clustering step, all preprocessing and analysis were implemented in Python (code is available on publication).

The clustering was done using the program VosViewer, where the generated clusters correspond directly to the generated layout of nodes (Waltman et al. 2010). We experimented with different numbers of clusters (3, 4 and 5) generated by tuning the clustering resolution parameter of VosViewer. For each generated clustering, we judged how coherent each cluster is by looking at the titles of articles in each cluster. In the end, we decided on having three clusters (from 0.85 clustering resolution) as we find that this clustering provided a clear delineation between the different levels of analysis used by innovation scholars in studying the pharmaceutical industry. These levels of analysis explored the environment (macro), interorganizational networks (meso) and organizations (micro), belonging to the main perspectives taken by management scholars in their studies (Hitt et al. 2007). To identify the underlying topics within these main clusters, 
we applied the clustering once again, now with a higher resulting cluster count of nine (from 1.2 resolution). These nine clusters corresponded to nine research topics distributed under the three main clusters. We labeled each topic by examining the articles and the top keywords according to the TF-IDF weights in each nine sub-cluster.

In our investigation of each topic, we looked at the following: (1) The number of articles in the cluster, (2) the number of citations within the innovation journals dataset; (3) the number of citations in pharmaceutical journals (explained in the following paragraph); (4) the median year of publication; (5) the average annual increase in the number of articles in the last 10 years, measured on the basis of the slope of the linear regression line where $\mathrm{x}$ is the year of publication and y is the number of articles published from 2009 to 2018; (6) the top keywords in the cluster extracted from the TF-IDF matrix; (7) the most-cited article within the dataset; and (8) the most-cited article by articles in the cluster in general.

In the second phase, to further explore the diffusion of these studies in practitionerpublished journals, we conducted a short bibliometric analysis on the citing articles of the innovation articles collected in our original dataset. Using the Web of Science, we downloaded the citing articles in practitioner journals in the following categories: "Pharmacology \& Pharmacy," "Biotechnology \& Applied Microbiology," "Medicinal Chemistry," "Medicine, Research and Experimental," and "Medicine, Internal and General." As some of these journals occasionally cover other fields outside pharmaceutical R\&D—two examples being agriculture and pharmacy — we narrowed the citing articles further by restricting them to have to contain "drug*", "medicin*" and "*pharmaceut*" in their text. After further filtering, we thus obtained 220 articles distributed across the five Web of Knowledge categories (Fig. 4).

By far, the journal Drug Discovery Today had the most publications with 35 articles, followed by Expert Opinion on Drug Discovery with 10 articles (Fig. 5). However, many of the most cited articles came from Nature Reviews Drug Discovery.

These articles were then pre-processed and analyzed using the same steps as before involving the hybrid cluster analysis using their textual and citation data. Clustering the articles then produced 5 main research topics exploring different processes in drug development. To understand the themes of interest to practitioners, each cluster was analyzed.

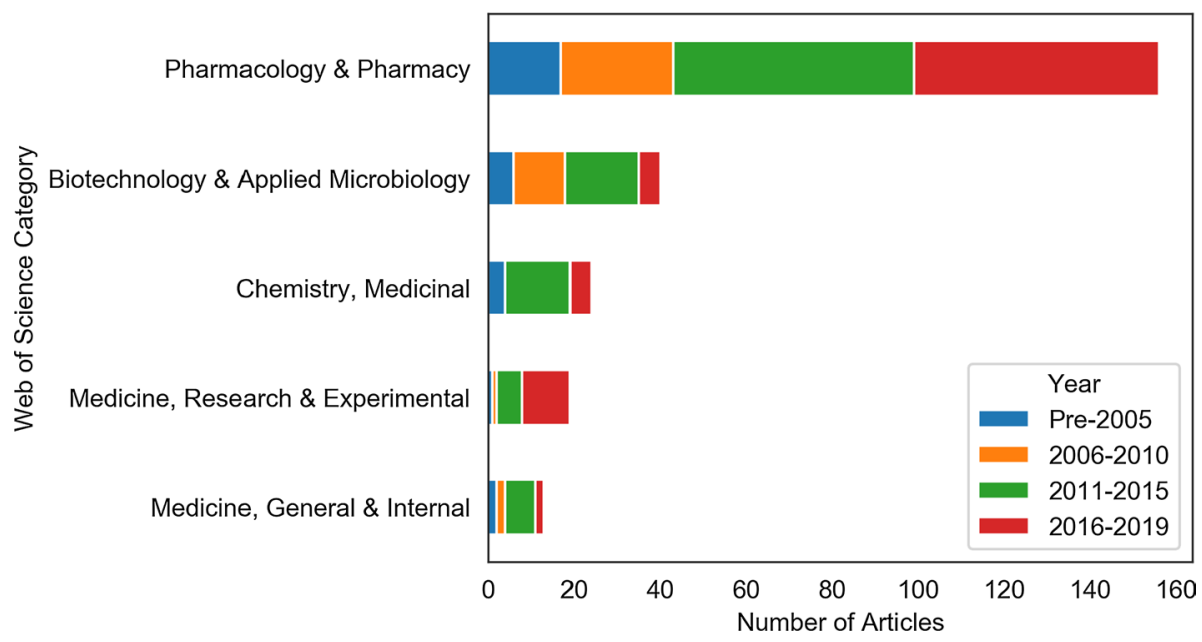

Fig. 4 Distribution of Articles among Practitioner Journal Categories 


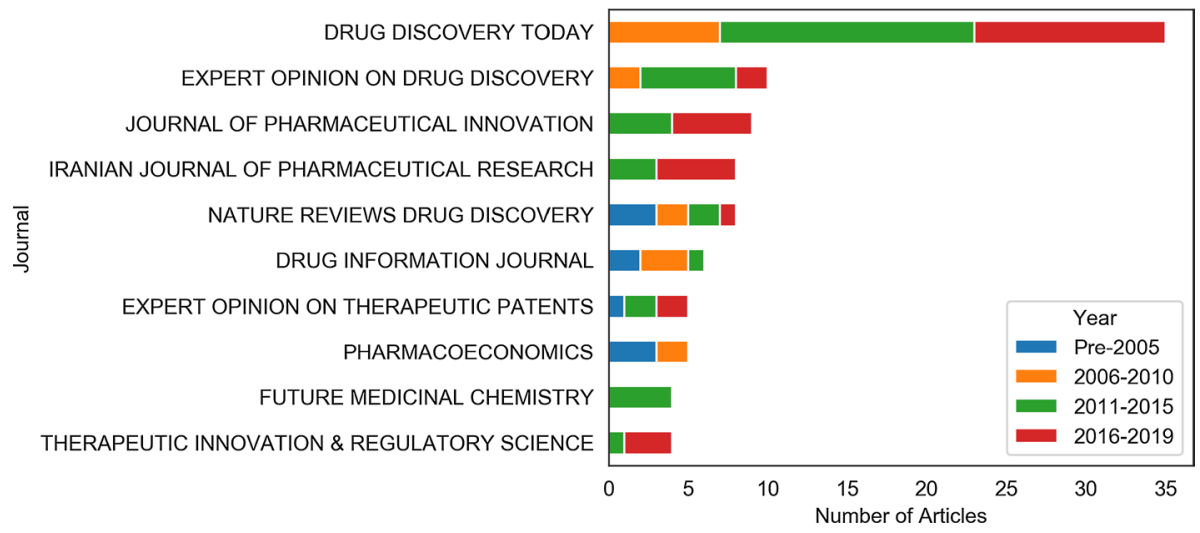

Fig. 5 Top 10 Practitioner Journals by the Number of Articles

Finally, we created a Sankey diagram (Bogart 2018) to show how practitioner articles cite innovation journal articles, by respective topics. We then constructed a framework containing the topics from practitioner journals and innovation journals, showing areas that can be explored for further research.

\section{Innovation in pharmaceutical R\&D}

As in Fig. 6, the steady increase in the number of publications over time reflects innovation scholars' increasing interest in the pharmaceutical industry. More importantly, the increasing number of articles citing these innovation studies in pharmaceutical journals reflects the greater interest among practitioners since approximately 2010.

Figure 7 shows the hybrid network from these innovation articles' textual and citation data. It shows that the articles are distributed relatively equally across three clusters,

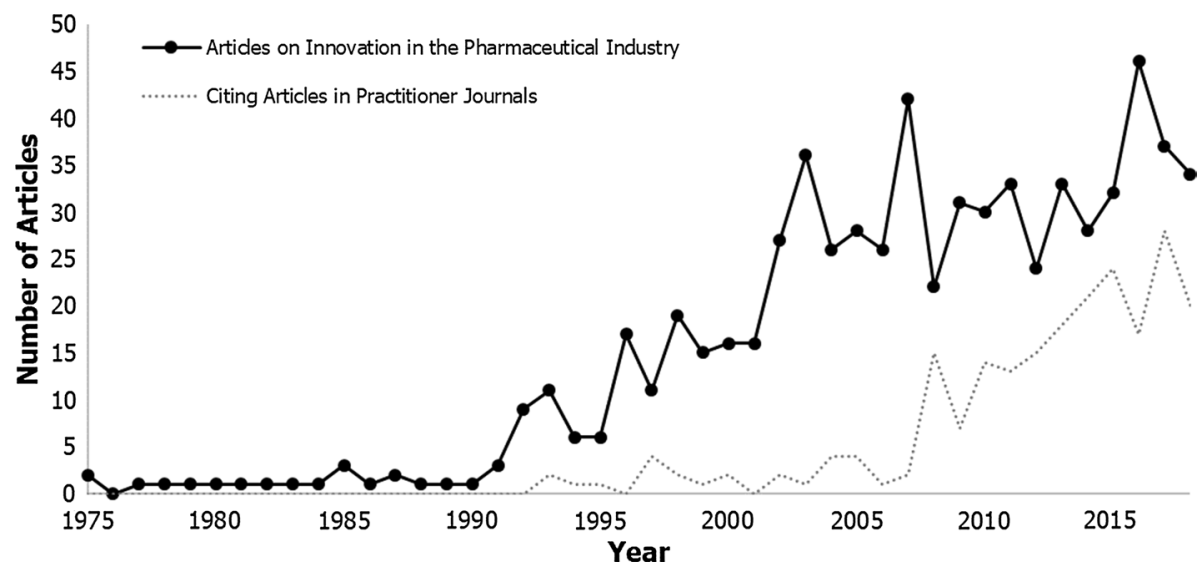

Fig. 6 Number of publications studying the pharmaceutical industry in innovation journals and citing articles in practitioner journals per year 


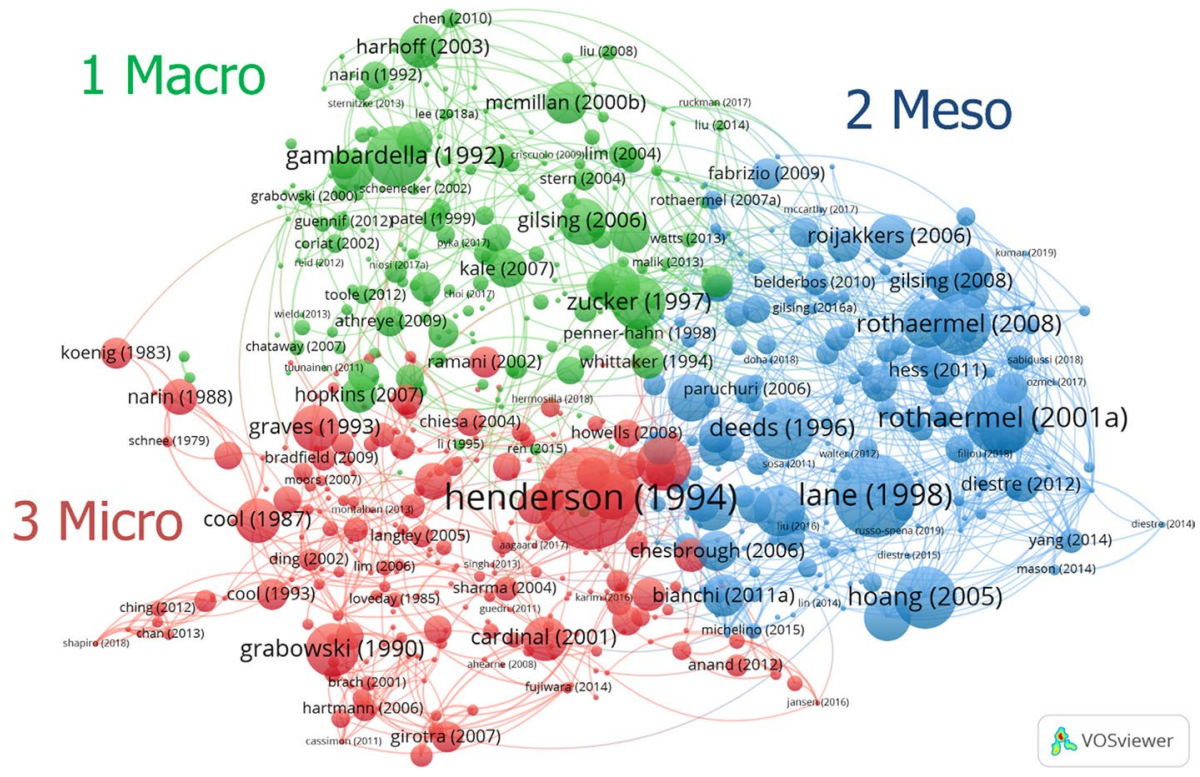

Fig. 7 Hybrid network of articles published in the top innovation journals on the pharmaceutical industry. Each node represents one article, labelled by the last name of the first author and the year of publication. The color of each node was generated from VosViewer clustering, corresponding to the level of analysis used. The size of each node shows the internal citation count of each article by other articles within the same network

each with at least 200 articles. The importance of all the perspectives on the study of pharmaceutical R\&D is suggested by the fact that the most-cited articles are distributed across the various clusters. We identify these three main clusters as Macro, Meso and Micro. These correspond to the level of analysis used by innovation scholars in their study of the pharmaceutical industry.

We summarize the data for each cluster in Table 1. As shown, cluster 1 pertains to the Macro level, which consists of studies examining the large-scale forces influencing innovation in the industry. The most relevant keywords at this level capture themes related to policy (e.g. "policy," "market" and "patent") and geography (e.g. "japan", "country"). Cluster 2 refers to the Meso level, which explores the relationships among the different organizations in the industry. This emphasis on collaboration is reflected in keywords such as "alliance," "partner" and "network." Finally, cluster 3 on Micro explores the innovation processes within firms, with keywords reflecting themes such as strategy (e.g. "management," "strategy" and "risk"); and product development (e.g. "product," "process" and "project”). The most relevant journals in terms of the number of publications were Research Policy for Macro, Strategic Management Journal for Meso and $R \& D$ Management for Micro, reflecting our intuition on the content of each cluster.

It is interesting to note that, although the literature could be structured in the many ways, the principal dimensions into which the pharmaceutical innovation literature is divided by our clustering are those denoting the level of analysis. For instance, if the typologies followed other studies of innovation (e.g. Crossan and Apaydin 2010), this literature could 


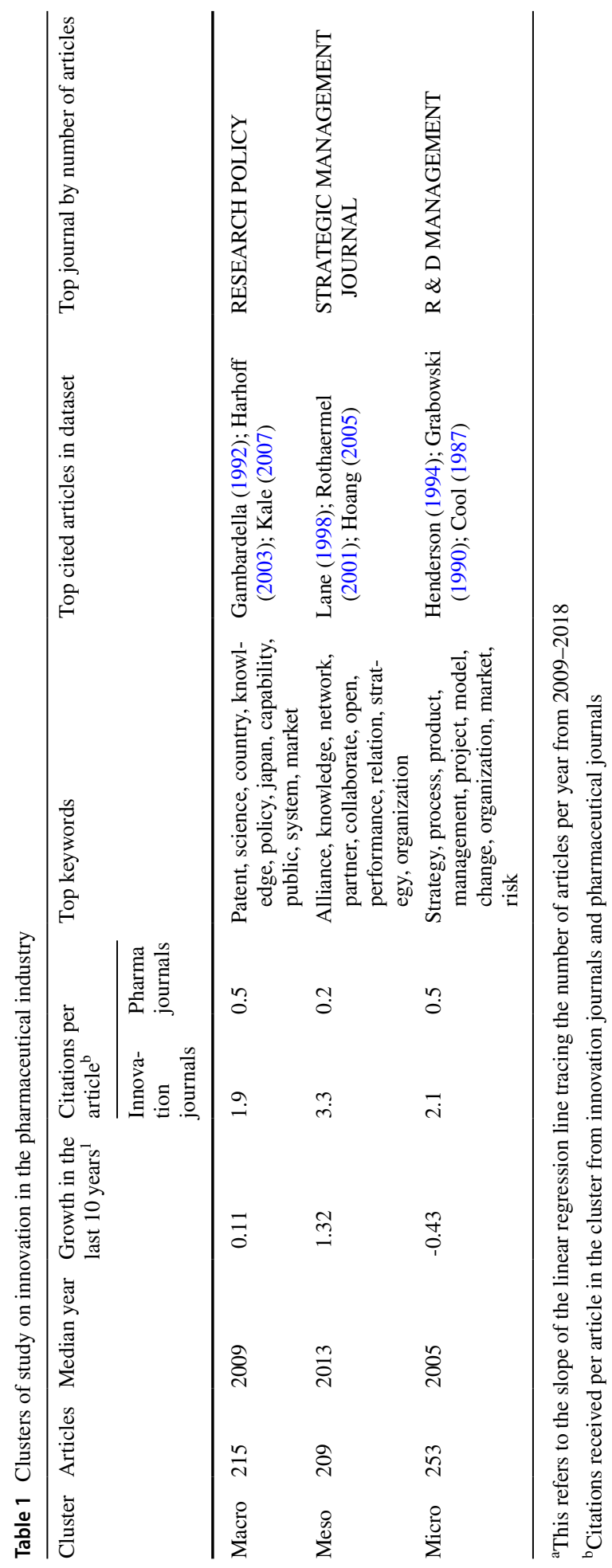


have been divided into other dimensions, such as processes (e.g. adoption, production, assimilation or exploitation) or nature (e.g. drug vs. service vs. enabling technologies).

To determine the amount of activity and the relative importance of each cluster to the literature as a whole, we tallied the number of articles and citations per cluster over time (Fig. 8). The Macro cluster has received steady interest from both innovation scholars and practitioners as shown by the increase in publications and citations over time. Looking at the trends however, the Meso cluster has received the largest growth in activity from innovation scholars. In terms of interest from practitioners, it has been catching up only recently. In contrast, despite a decrease in the number of publications, the high number of citations among pharmaceutical journals shows that the Micro cluster is still the most important topic for practitioners.

Under each of these 3 clusters, we find 9 research topics distributed among them: Innovation System and Knowledge Transfer in the Macro cluster; Strategic Alliances, Collaborative Networks, Competitive Advantage and Open Innovation in the Meso cluster; and Organizational Learning, Strategic Groups and Product Management in the Micro cluster. These topics are organized in Fig. 9:

In the following section, we provide an overview of each research topic, summarizing its major themes and exploring how they are situated within the innovation landscape. While these clusters were categorized based on the level they focus on, we note that there is a high degree of overlap across them. Nonetheless, despite the lack of hard boundaries, these clusters are still instructive, as they show the main themes according to which we can structure the literature.

\section{Macro}

Under the macro cluster, we find two research topics: Innovation System and Knowledge Transfer (Table 2).

Innovation Systems, the larger of the two topics in the number of publications, refers to networks of actors and institutions that create, diffuse and use innovations (Carlsson et al. 2002). As implied by the occurrence of keywords such as "japan," "india" and "country," this topic covers the geography-dependent factors that affect the innovation processes within the pharmaceutical industry such as research policy, cultural norms, scientific institutions and the regulatory environment. In many studies of national innovation systems (Lundvall 1993; Nelson 1993), countries with developed pharmaceutical industries,
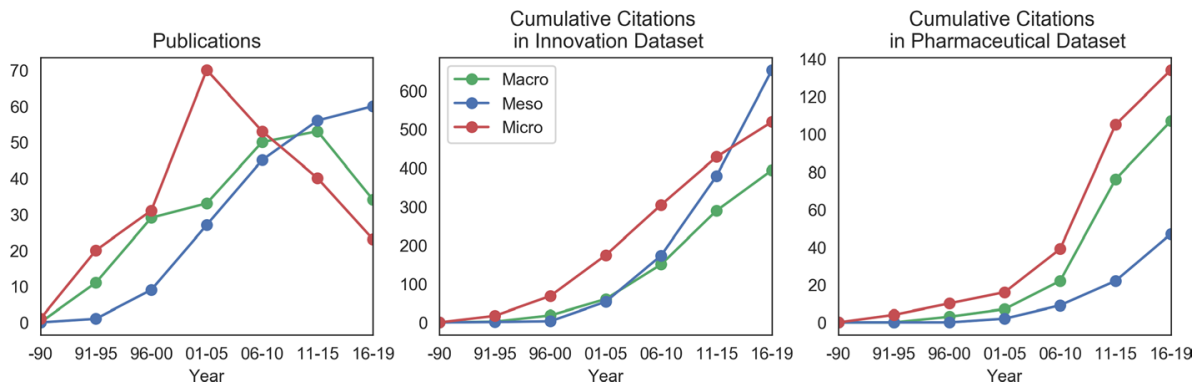

Fig. 8 Number of publications (left), cumulative citations within innovation journals (center) and cumulative citations in practitioner journals (right) per cluster over time 


\section{Environment}

Knowledge Transfer

Innovation System

\section{Macro}

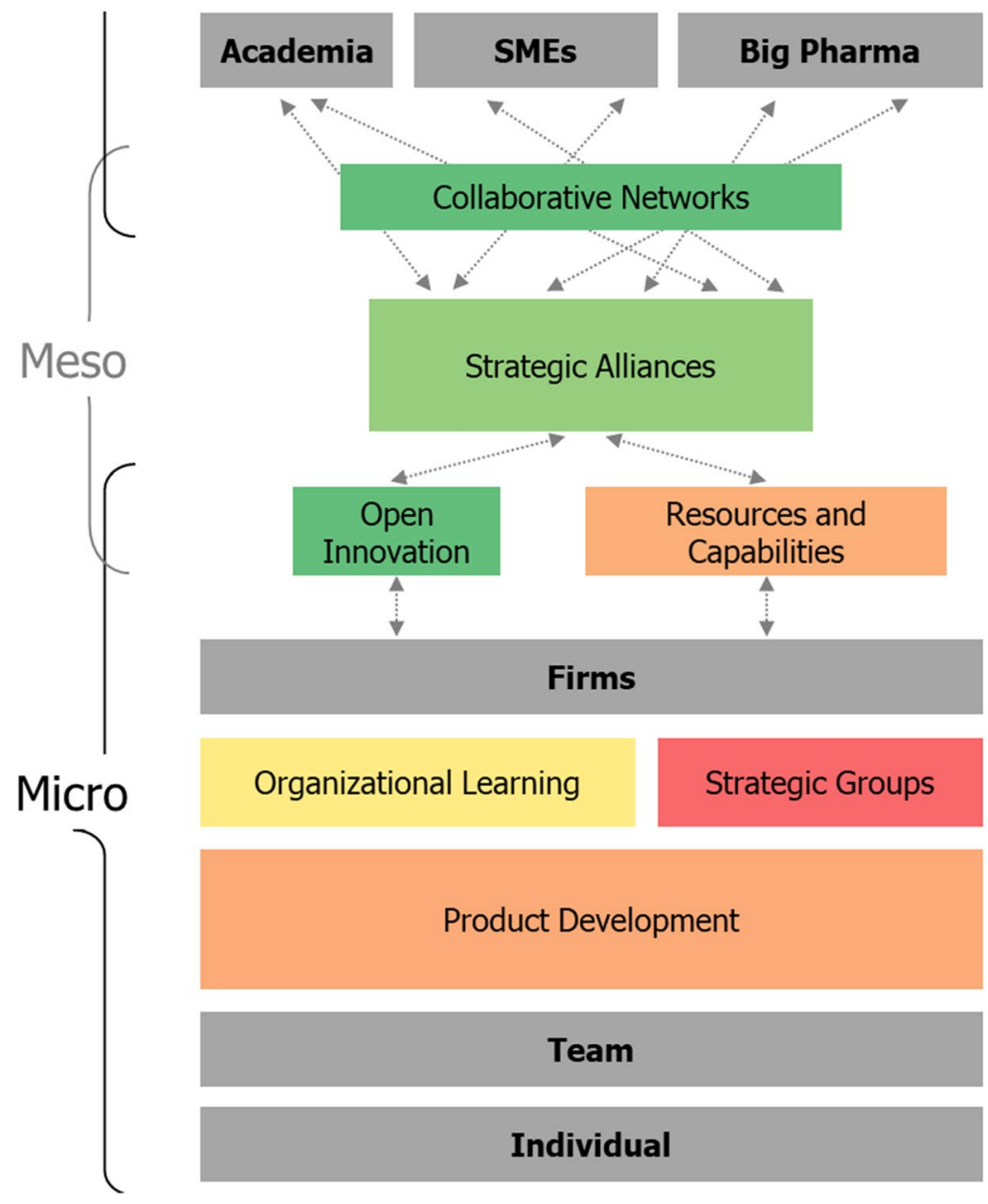

Fig. 9 A framework integrating innovation research on the pharmaceutical industry. The research topics are grouped by their level of analysis. The size of the box reflects the number of articles. The colors in the bar for Median Year indicate how the focus of articles shifted between 2000 and 2014

typically in the West, are compared in terms of their competencies, policies and regulatory environments. Recently, the increasing involvement of countries such as China, India and Brazil in drug development has made innovation scholars study their catch-up with regard to building capabilities in the pharmaceutical sciences (e.g. Athreye et al. 2009; Guennif and Ramani 2012). 


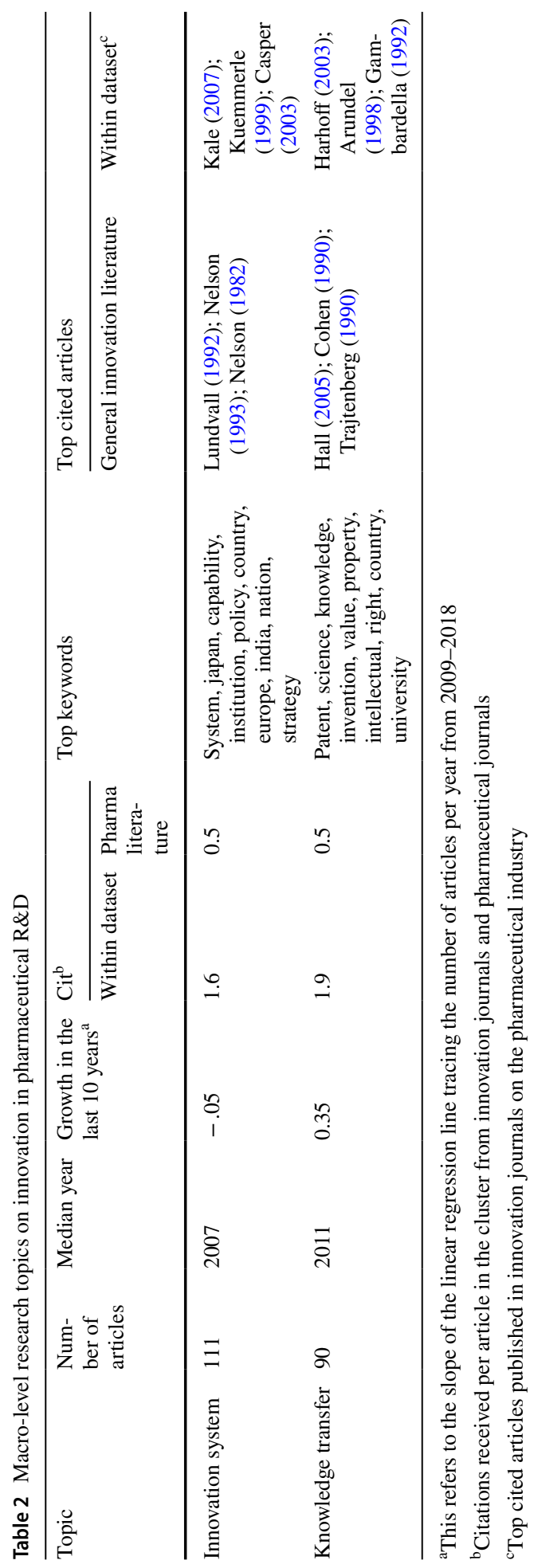


The second Macro topic, Knowledge Transfer, contains two important sub-themes: the intellectual property regime ("patent," "intellectual" and "right") and basic research ("university" and "science"). The industry has one of the highest patenting rates, with an estimated $80 \%$ of its product innovations being patented (Arundel and Kabla 1998). Due to its reliance on intellectual property protection to appropriate value from knowledge (Mansfield 1986), a wide range of studies on them have emerged, for example on the creation of models for their proper valuation, on their roles in signaling firms' R\&D activities to shareholders, and on managing patent portfolios as part of the strategy. There has also been increased interest in studying how industry practices are affected by policies on intellectual property and technology transfer such as Trade-Related Aspects of Intellectual Property Rights, the global agreement known by the abbreviation TRIPS (e.g. Lemus and Marshall 2018; Vakili and McGahan 2016).

The second sub-theme under Knowledge Transfer investigates the role of basic research in bringing new drugs to the market (e.g. Gambardella 1992; McMillan et al. 2000). Such exploratory research, which aims to uncover the biological mechanism of diseases, is mainly conducted by universities and public research institutes as the high uncertainty and lack of a clear path towards commercialization make it unappealing for industry (Rafols et al. 2014). Consequently, innovation research primarily focused on how scientific knowledge can be effectively transferred from academia to industry (e.g. Gambardella 1992). Recently, however, academia has expanded their involvement in the drug development process through initiating research collaborations, creating spin-offs and even performing drug discovery itself (Tralau-Stewart et al. 2009). To keep up with such trends, it is thus crucial for innovation scholars to study this evolving nature of the relationship between academia and industry.

\section{Meso}

Under the Meso cluster, we identify the following research topics: Strategic Alliances, Collaborative Networks, Open Innovation and Resources and Capabilities (Table 3). The topic Strategic Alliances study various aspects of alliances in the industry including the various processes, stages, antecedents and characteristics of participating actors. These alliances can be mapped to show the structure by which the various pharmaceutical firms are connected in the topic Collaborative Networks. In contrast to this large-scale analysis, alliances can also be examined from the point of view of the firms that engage in them such as in the topics Open Innovation and Resources and Capabilities. Below we discuss each of these topics, exploring their differences in focus.

Of all research topics, Strategic Alliances has grown most in the last ten years, not only in terms of size, but also in its impact to the innovation literature as measured on the basis of citations. Examination of the keywords under this topic such as "alliance," "partner," "experience" and "collaborate" reveals a focus on the activity itself. Due to the increasing complexity of the R\&D process, firms are required to collaborate (Powell et al. 1996; Rothaermel and Boeker 2008). Accordingly, many articles in this cluster analyze each phase of an alliance, from its initiation to its management and the evaluation of its performance and investigate the factors for their success (e.g. Hoang and Rothaermel 2005; Lane and Lubatkin 1998). In the pharmaceutical industry, there are different actors with different specialized competencies: universities in basic research, small companies in early drug discovery and large pharmaceutical firms in late drug development and marketing (Bianchi et al. 2011; Stuart et al. 2007). Aside from 


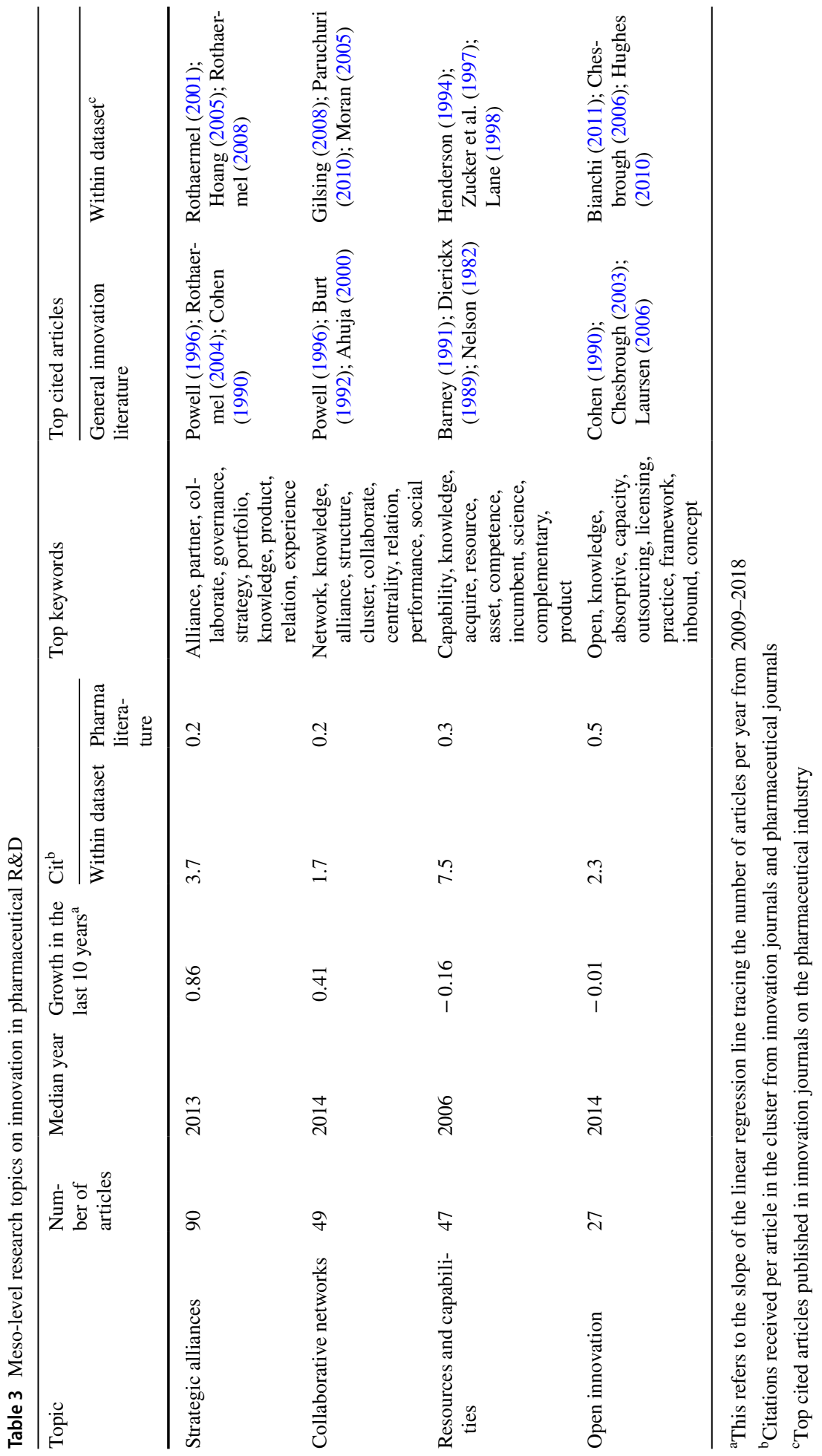


enabling drug development to progress forward, firms engaging in these alliances also have a secondary goal to extract crucial knowledge from their partners (Powell 1998). With the variety of modes of collaborations possible across the industry, the different actors have to consider carefully when to engage in such alliances and how such collaborations can help them in their route to bringing a new drug to the market. Correspondingly, innovation scholars have explored drivers of partnership initiation and partner selection. This has even prompted a debate in the management community whether smaller biotechnology startups or the larger pharmaceutical firms have the upper hand in initiating such collaborations (Diestre and Rajagopalan 2012; Mason and Drakeman 2014). With firms engaging in many such alliances at any given time, there has been an increasing scholarly interest in understanding how to effectively manage the firms' portfolio of alliances (e.g. Van de Vrande 2013).

In the Meso cluster, the topic of Collaborative Networks is also growing. Unlike the previous topic, Strategic Alliances, which focuses on the collaborations themselves, Collaborative Networks situates collaborations against the broad context of the other collaborations occurring across the industry (Gulati 1998). Rather than looking at an alliance in isolation, networks use a wider perspective that is reflected in keywords such as "network," "structure" and "centrality." To study these collaborations in aggregate, scholars use various network-analysis tools, mapping individuals or organizations as nodes linked by sets of social relationships. These networks can be recreated from various data sources, most commonly patents, publications and mergers and acquisitions. One area that is much explored is how networks facilitate the diffusion of technology (e.g. Gilsing and Nooteboom 2006; Orsenigo et al. 2001). Such studies typically raise the classic debate on the importance of structural holes (Burt 1992) and redundant network structures (Coleman 1988) in innovation. In any case, there is a greater appreciation of the active role that individuals and firms could take in situating themselves to have a central location within such networks (e.g. Dong and Yang 2016). Moreover, scholars have also examined other networks apart from interorganizational networks, including the network formed from the collaborations between scientists within an individual firm (e.g. Grigoriou and Rothaermel 2017).

Over the last 20 years, Open Innovation, which refers broadly to the opening of a firm's boundaries to external innovation (Chesbrough 2003), has gained great interest in the pharmaceutical industry. As a concept that has considerable overlaps with the topics discussed above, open innovation has also received some criticism. First, since firms in the industry have always relied on collaboration, it has been labelled as old wine in a new bottle (Trott and Hartmann 2009). Believing mistakenly that it means open-source and thus a lack of intellectual property protections, many drug development practitioners also remain hesitant to use the term (Hunter and Stephens 2010). But despite these criticisms, open innovation has been an important construct that reflects the increasing relevance of externally derived innovation for pharmaceutical firms (Bianchi et al. 2011). While this is a broad multi-level research topic, our analysis of its application in the pharmaceutical industry suggests that it is studied often with the firm as the focal point. It has a particular focus on the different modes of relationship (such as "outsourcing" and "licensing") that these firms can use to engage with various knowledge sources such as academic institutions, biotech startups and large pharmaceutical companies. With this firm-centered view, a major construct relevant to the topic of open innovation has been absorptive capacity, which is defined as a firm's "ability to recognize the value of external knowledge, assimilate it, and apply it to commercial ends" (Cohen and Levinthal 1990). In fact, due to its importance, Cohen and Levinthal's (1990) landmark paper is the most cited article on our dataset. With the evolving nature of how new knowledge is absorbed by firms in the industry, absorptive 
capacity has been revisited many times by innovation scholars-who, for instance, have traced its industry-specific process (Patterson and Ambrosini 2015). As the industry continues to shift towards collaborations, we see a greater convergence and integration of the Meso level with other levels of study.

While it is much cited in the dataset, the topic of Resources and Capabilities has not grown as much in recent years. Unlike the Meso topics above, which focus on the collaborative relationships between the firms in the industry, Resources and Capabilities focuses on the competition between firms. To gain competitive advantage, firms differentiate themselves from other firms (e.g. Henderson and Cockburn 1994; Thomke and Kuemmerle 2002). A central aspect of this topic is the resource-based view that traces firms' competitive advantage to their control of valuable, rare and novel resources (Barney 1991). Correspondingly, keywords in this topic include "asset," "knowledge" and "product." However, the increasing reliance on the outside world is also reflected in this topic-which explains the occurrence of the keywords "acquire" and "complementary." The importance of assimilating capabilities from external sources explains why Resources and Capabilities was allocated to the Meso level in our analysis, even though it seemed to fit better with the Micro level. This paradox highlights the need for further research on how, as part of their strategy, firms can manage the tension between competing and collaborating across different technological fields and therapeutic areas within the industry.

\section{Micro}

The Micro cluster contains three research topics that explore different parts of firm innovation: Product Development, Organizational Learning and Strategic Groups (Table 4).

In terms of the number of publications, the largest research topic found is Product Development. Keywords in this topic—such as "product," "project" and "process"-all relate to the management of the product development process, especially with regard to bringing new drugs to the market. Exploring the intricacies of the drug development process, this broad topic examines a variety of themes. One of these themes is the management of projects within firms, paying particular attention to managing the high failure rates in the drug development process (e.g. Grabowski and Vernon 1990). Due to the number of $R \& D$ projects in which a firm is engaged at any given time, investigating methods to manage effectively this portfolio is also important (e.g. Blau et al. 2004; Jacob and Kwak 2003). While Product Development previously had a high priority for innovation scholars examining the pharmaceutical industry, the low growth in the number of publications suggests that this focus has now been diminished. However, this does not mean that Product Development is no longer of interest to innovation scholars. Instead, we can argue that the framing or focus when analyzing product development has shifted. Previously, articles explored the process itself, looking at the specific practices firms apply internally. Research thus focused on various ways of optimizing the different steps involved in product development. However, as we saw in the previous discussions, innovation scholars have, as the pharmaceutical industry embraces external innovation, become more interested in the Meso level. Rather than analyzing research directly within the firm, innovation scholars have been more interested in a meta-level exploration of the ways in which in-company product development interacts with the external world. Thus, while Product Development remains a crucial issue, innovation scholars' focus has shifted to capturing how drug development is influenced by various external developments such as in technology (e.g. Hopkins et al. 2007), regulation (e.g. Rzakhanov 2008) and marketing (e.g. Liu et al. 2016). 


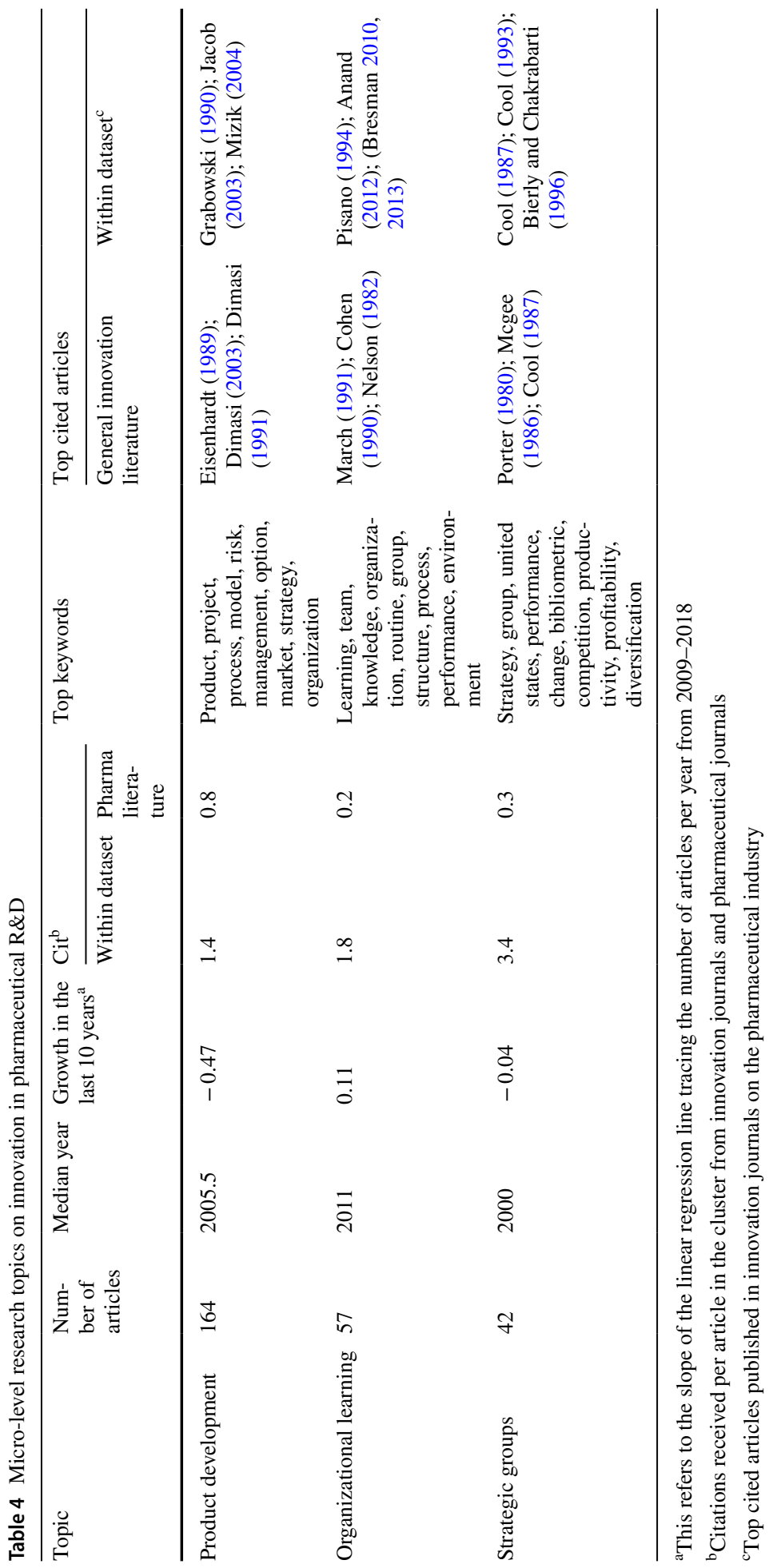


The next research topic, Organizational Learning, has grown steadily in recent years. It is related to the systems and routines firms have in place for generating, retaining, managing, utilizing and transferring knowledge (March 1991; Pisano 1994; Santos 2003), demonstrated by keywords such as "knowledge," "learning” and "process." Scholars are thus interested in studying how various features of organizations enable them or impede them in coping with new knowledge. Scholars also explore how these organizational routines can change (Anand et al. 2012; Bresman 2013). To differentiate this topic from the previous Meso topics which are concerned with knowledge outside the firm, Organizational Learning focuses on the stage where knowledge is already within the boundaries of the firm. Especially for large firms with multiple laboratories worldwide, it is important that valuable knowledge diffuses across its various departments and are thus, integrated and applied towards various projects.

Strategic Groups, the final research topic in the Micro cluster, is the oldest of all research topics, and has not attracted much interest among innovation scholars in recent years. This topic focuses on classifying firms into various categories, and dissecting the similarities and differences in strategies and performance within and across groups (Bogner et al. 1996; Cool and Dierickx 1993). However, as innovation scholars now study the industry as a whole rather than intending to segment it further, this topic has gone out of fashion in the innovation literature.

Overall, in the last 10 years, there has been a relative stagnation in studies at the Micro level, partly because of the emphasis on innovation at the interorganizational level. Deeper levels of analysis are possible, such as the study of units, teams and individuals. Unfortunately, we found that such deeper-level analyses are not so common in the pharmaceutical industry. Unlike the synthesis by Crossan and Apaydin (2010), which shows leadership to be an important determinant of innovation, the pharmaceutical R\&D literature seems to have placed less focus on this. However, due to the importance of highly skilled individuals (Cowlrick et al. 2011; D’Este and Perkmann 2011; Liu et al. 2015) and teams (BenMenahem et al. 2016; Bresman and Zellmer-Bruhn 2013; Stryker et al. 2012; Tang 2016) in innovation, this is an important area for further exploration.

\section{Innovation topics in practitioner journals}

In the second phase of this study, we identified the research topics valued by practitioners by examining the citing articles of the innovation studies we have presented above. Based on this new set of articles, we formed a similar hybrid network, which is shown in Fig. 10. This identified the following five innovation topics published in practitioner journals: Research Productivity, Technology Transfer, Process Management, Clinical Development and Healthcare Marketing.

These research topics are summarized in Table 5. Research Productivity and Process Management are concerned with the management of the entire drug discovery and development process. In contrast, certain topics are much more relevant in specific phases, such as Technology Transfer in early drug discovery, Clinical Development in the drug development stages, and Healthcare Marketing after a drug receives approval.

As the industry depends on R\&D to bring new drugs to the market, Research Productivity is the largest topic of interest to practitioners. It involves measuring and diagnosing factors that affect R\&D productivity. In the years soon after 2010 , there was a focus on the decline in productivity brought to the industry by the increasing cost of developing new 
drugs (Paul et al. 2010; Scannell et al. 2012). Various factors were associated with this productivity decline, including the discovery of treatments for so-called low hanging fruits, the increased standard needed for new drugs compared to current drugs in the market, the overinvestment in basic research despite the many biological uncertainties (Pammolli et al. 2011; Scannell et al. 2012). To address such issues, studies have also explored new R\&D models that can be embraced by companies to improve their R\&D return such as embracing open innovation (Moors et al. 2014; Schuhmacher et al. 2016). In response to practitioners' interest, innovation scholars could help to further ideate new models and evaluate these models' potential in revitalizing the drug pipeline of firms.

While the topic of Process Management also concerns the entire drug discovery and development process in firms, it focuses more on the technical implementation of each step. Compared to the other research topics covered by practitioner journals, we find this topic to require deep domain knowledge, covering specific scientific problems such as chemical synthesis, drug formulation and quantitative analyses of portfolios. In other words, rather than assessing R\&D from a meta-level, articles under Process Management aim directly to identify the best practices in conducting drug development. However, it is important

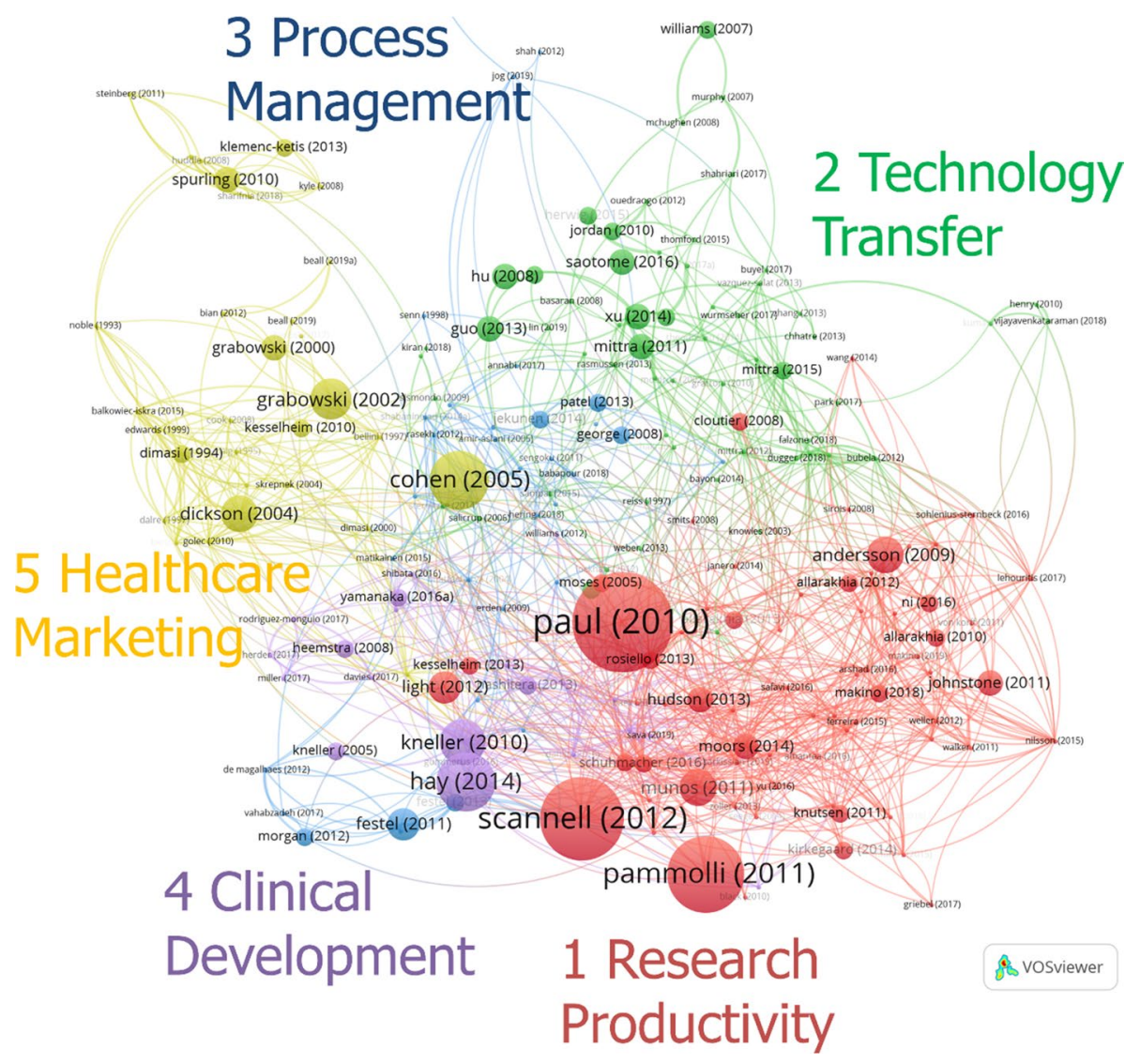

Fig. 10 The hybrid network of citing articles in practitioner journals. Articles are labelled by first author and year. Colors show different clusters of study in VosViewer clustering. The size of each node indicates the internal citation count of each article by other articles within the same network 


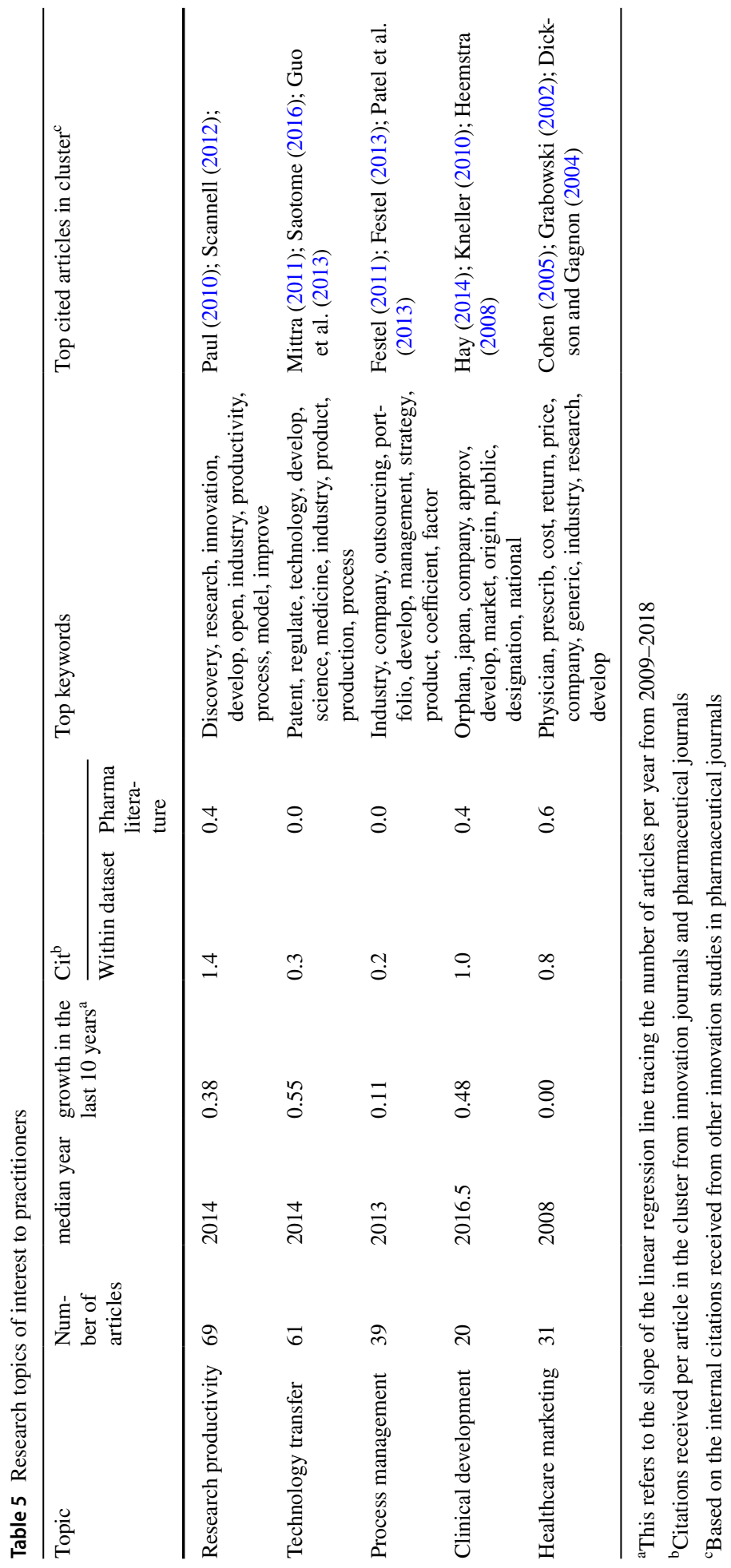


to note that this also has evolved, placing much more emphasis on the role of external innovation. For instance, they explore options such as outsourcing for certain processes (e.g. Festel 2013). As this is a domain-specific topic, innovation scholars might not be as interested in exploring such niche matters. Despite this, we still recommend scholars to peek into the black box of such processes, as fresh sets of eyes may generate new insights for practitioners.

The topic of Technology Transfer has grown the most across the practitioner topics. Parallel to the topic Knowledge Transfer in the innovation literature, it is also concerned with the scientific advances surrounding the industry (e.g. Mittra et al. 2011) and the role of intellectual property protection to exploit such advances (e.g. Saotome et al. 2016). This topic has received mutual interest from both practitioners and innovation scholars as seen by the number of publications. Due to the value of generating basic research and transferring the knowledge this generates to the industry, we expect this research topic to attract continued interest.

The topic of Clinical Development is related to the latter parts of drug development, in which a lead candidate is tested for efficacy and safety. Eventually, only one drug in ten that enter this phase gets approval (Hay et al. 2014). Due to the high regulatory burden in this respect, the industry is concerned about how to navigate complex institutional requirements to bring a drug to the market. At the same time, this topic also explores how such institutional factors influence the types of $R \& D$ projects that firms engage in. For instance, countries' favorable policies concerning orphan drugs have made it possible for new firms to participate in such areas (Heemstra et al. 2008; Kneller 2010). As this a relatively young research area in practitioner journals, there are many areas for further research. For example, innovation scholars might find the feedback loop between regulations and the therapeutic areas that firms invest in their R\&D to be an interesting subject for further studies.

Healthcare Marketing focuses mainly on the interaction between the pharmaceutical industry and the healthcare system in different countries. Overviews of drug sales across various therapeutic areas are common in this topic (Cohen 2005). They also explore the marketing tactics that firms use to reach patients that need these treatments. Due to greater scrutiny of industry practices, this topic also includes discussions on the innovativeness and cost efficiency of drugs. Although our analysis suggests that this topic is the oldest, this impression is due largely to the statistical effect of many older analyses of drug introductions. In fact, there have been recent studies of this topic, demonstrating the interest of $\mathrm{R} \& \mathrm{D}$ practitioners in these matters. Thus, innovation scholars then can explore further how the two-marketing and R\&D — can interact in order to improve the drug development process within firms.

\section{Towards highly engaged innovation research}

As implied by the previous sections, the emphasis on pharmaceutical R\&D innovation differs between innovation journals and pharmaceutical journals. While innovation scholars are interested mainly in gaining potentially generalizable insights on innovation by exploring the industry, practitioners in the pharmaceutical industry are concerned primarily with improving their research practice. In turn, the topics that interest them are directly related to the specific processes in the drug development process - from target identification to the approval of drugs. 
Despite such differences, the number of citations (see Fig. 6) shows that practitioners are increasingly interested in innovation research. However, as we show in the mapping of citations in Fig. 11, this interest is compartmentalized within certain topics. As one would expect, most practitioner topics cite the innovation topic Product Development, since this delves most into the complexities of the pharmaceutical development process. Other topics in the Macro cluster, including Innovation System and Knowledge Transfer, have also attracted interest in specific practitioner topics. On the other hand, whereas the Meso cluster has been receiving increased attention in the innovation literature, such interest has not been apparent in the practitioner literature. This low diffusion shows that there is potential for more engaged and relevant studies for innovation scholars on the pharmaceutical industry.

To increase the relevance of innovation research in pharmaceutical $R \& D$, we propose the matrix in Fig. 12. This shows how specific processes in the pharmaceutical industry could be further explored by innovation scholars to gain new insights on their respective topics of interest while maintaining relevance for practitioners. The matrix has two axes, the areas in the pharmaceutical industry studied (horizontal axis) and the levels of analysis in innovation research (vertical axis).

The R\&D process to bring a new drug to the market is mired with high complexity and high failure rates. To illustrate the long path a drug has to take to reach the market, we briefly describe the drug discovery and development process (Paul et al. 2010). The first step involves the identification of a target disease and its underlying mechanisms. Once a protein has been identified as a suitable target for a drug, teams of scientists then work together to design a lead compound that can act on the target. Once there is a promising lead, it can then be tested for efficacy and safety in cell and animal models. Once a lead has been identified as a potential drug, it then enters the drug development process, where it undergoes clinical testing in humans. This development phase consists of three phases and is strongly regulated by the authorities (Vinet and Zhedanov 2011). Phase I consists of clinical trials in which toxicity is tested in a small number of healthy volunteers. Phase II consists of treating patients with the disease to test the drug's safety, and, preliminarily, its efficacy. Finally, to establish the drug's efficacy and discover possible side effects, it is tested in phase III trials in a large sample of patients. Once approved, the firm then has to manufacture and market the drug to ensure that it reaches its patients.

The first avenue for further research would be to have a detailed exploration of a particular process or technology in drug discovery and development through an innovation topic of interest (Fig. 12, Label 1). Since most innovation studies treat the R\&D process as a black box, such an investigation of a specific process could provide new insights that would help practitioners and potentially enrich their understanding of innovation. While this has already happened in a few case studies on specific technologies such as RNA interference (Natsukawa et al. 2013), lab-on-a-chip (van Merkerk and Robinson 2006) and gene therapy (Kapoor and Klueter 2015), such in-depth analyses are not as common. Yet, from our analysis, we show that practitioners value such engaged research as these enable the practitioners to view their innovation activities in a new light. Since we show that the meso-level has seldom been cited by practitioners, innovation scholars can examine various facets of collaborations occurring in specific processes in the pharmaceutical industry to increase the relevance of such meso-level studies to practitioners.

Apart from studying a particular pharmaceutical area from one innovation perspective, innovation scholars can analyze it from a multilevel perspective (Fig. 12, Label 2). By exploring the environment, interorganizational relationships and organizational practices 


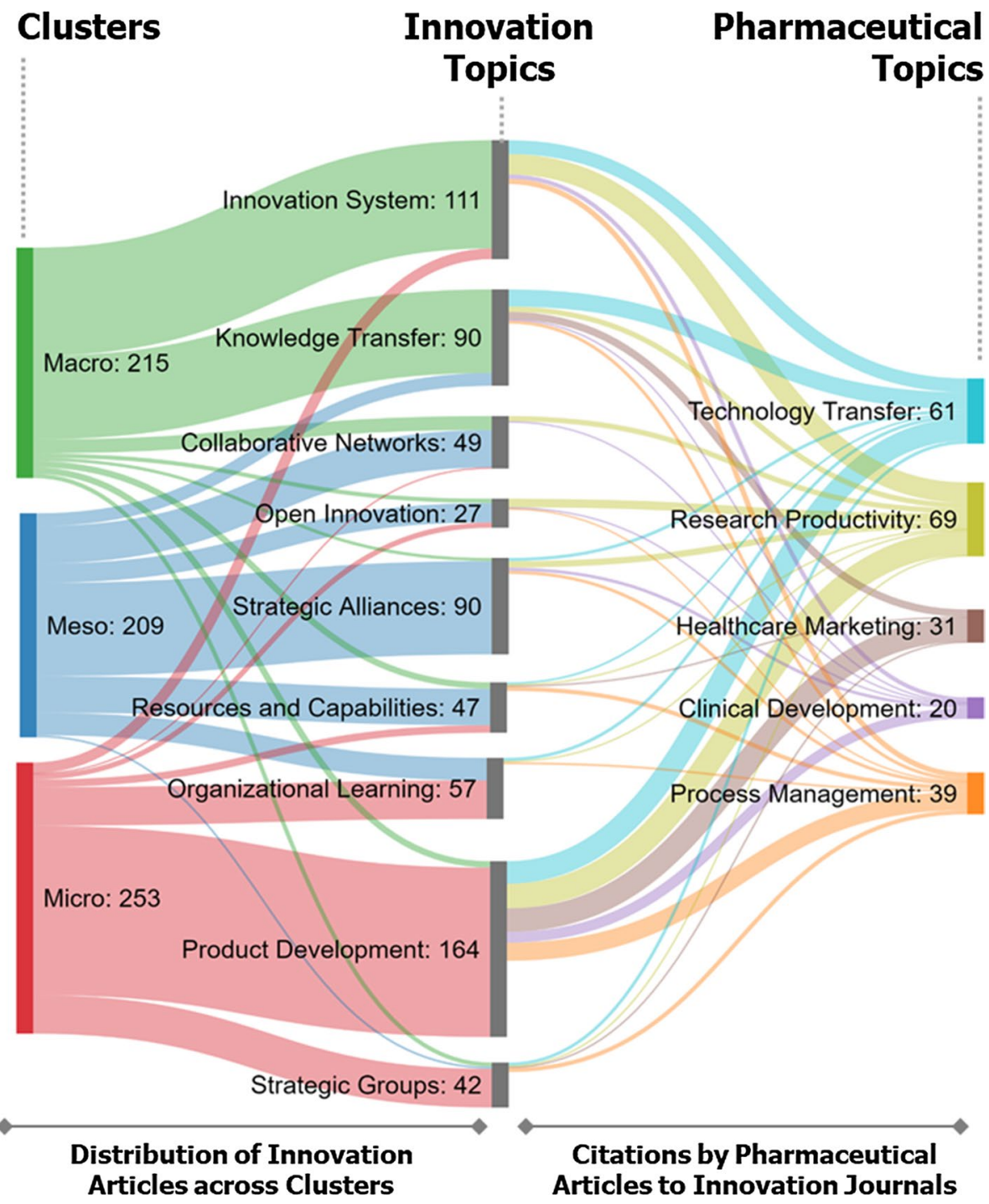

Fig. 11 Mapping research articles according to their distribution among the major innovation clusters and research topics (on the left) and distribution of citations per research topic in practitioner journals (on the right)

affecting a particular research area in the pharmaceutical sciences, innovation scholars can better inform scientists and managers on the issues they have to consider to improve their practice. Moreover, such multilevel analysis may also enable innovation scholars to gain a better understanding of the big-picture dynamics and microfoundations of a certain innovation topic. Exploring how these different levels interact for a specific process could also provide new insights (Fig. 12, Label 3A and 3B). As knowing which pharmaceutical area to explore requires insider knowledge, innovation scholars should look into engaging in research collaborations with industry practitioners. Increasing the extent of such 
collaborations would help innovation scholars to gain richer insight on specific processes by gaining access to relevant data from companies.

Finally, with the individual steps of the drug development process being highly interlinked, valuable insights might thus be produced by studying how such processes interact with one another. Innovation scholars can explore how practitioners involved in the early stages of drug discovery adjust their practice as they anticipate the requirements by their peers involved in the later stages (Fig. 12, Label 4A). They might also examine how downstream practitioners cope with the output of previous processes (Fig. 12, Label 4B). This can also be further extended by following the entire drug development cycle through a single innovation theory (Fig. 12, Label 5). Aside from gaining a complete picture of the drug development process, scholars can gain new insights on their innovation topic of interest by checking how robustly their theory applies through the different phases of drug development.

\section{Pharmaceutical Industry Process}

Drug Discovery

Drug Development

\begin{tabular}{|c|c|c|c|c|c|c|}
\hline $\begin{array}{c}\text { Target } \\
\text { Identification }\end{array}$ & $\begin{array}{c}\text { Lead } \\
\text { Discovery }\end{array}$ & $\begin{array}{l}\text { Preclinical } \\
\text { Trials }\end{array}$ & $\begin{array}{c}\text { Phase } 1 \\
\text { Clinical Trial }\end{array}$ & $\begin{array}{c}\text { Phase } 2 \\
\text { Clinical Trial }\end{array}$ & $\begin{array}{c}\text { Phase } 3 \\
\text { Clinical Trial }\end{array}$ & Approval \\
\hline
\end{tabular}

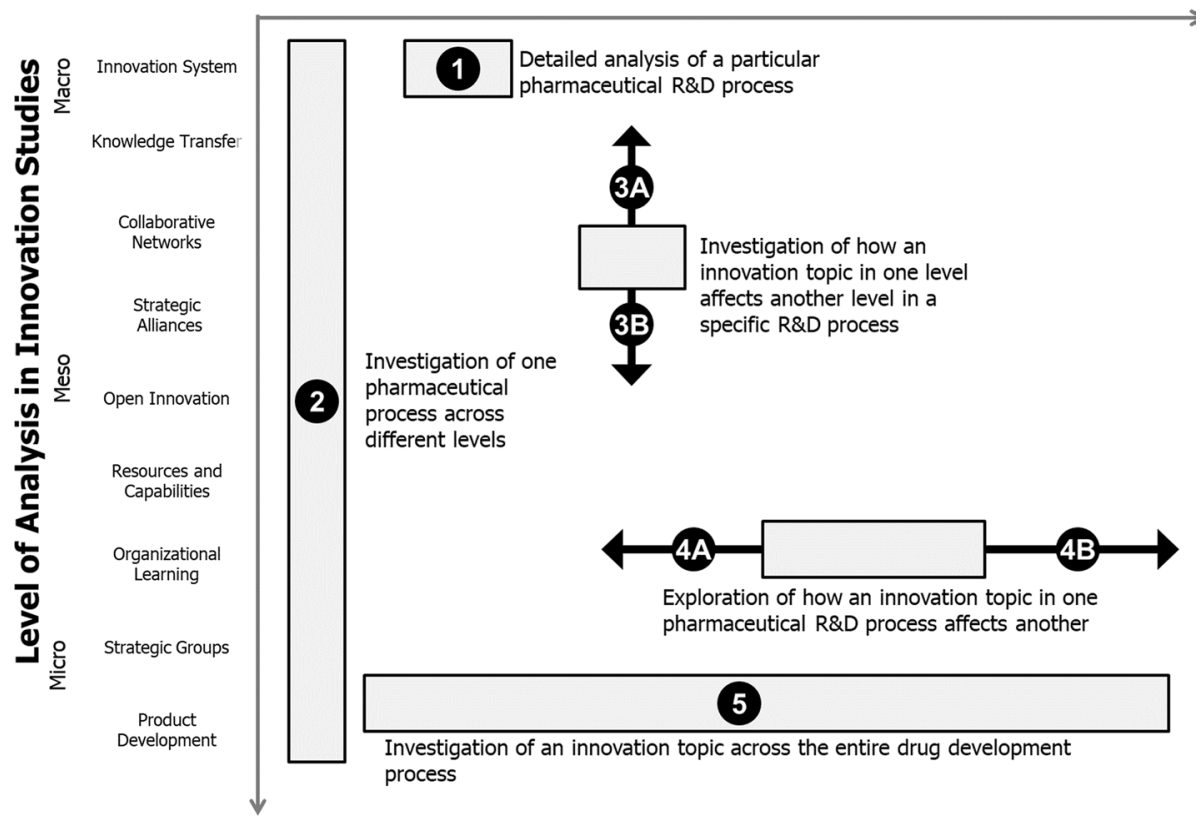

Fig. 12 A framework integrating innovation topics (left) and pharmaceutical industry processes (top) for future research avenues 


\section{Conclusions}

Innovation scholars continue to subject the pharmaceutical industry to extensive scrutiny. Given the continuous growth in the number of articles published per year, we conducted a bibliometric analysis that would map the structure of the literature and identify trends in research. We identified three main levels - Macro, Meso and Micro - at which the literature has assessed innovation over recent years. Between them, these levels comprise 9 research topics with different theoretical foundations and phenomena of interest. To trace the diffusion of ideas to practitioners, we analyzed the citing articles in journals published by practitioners in the industry.

We focus mainly on giving readers a top-down overview of the diverse range of research topics concerning R\&D in the industry. We trust that by exposing scholars to the pertinent issues in other fields, cross-fertilization of ideas can be facilitated for new insights. Due to the extent of the innovation literature on the industry, this study could only survey each research area at a surface level. Nonetheless, by highlighting the main issues and the most relevant papers in each area, the hope is that we give readers a head start should they decide to dig deeper into a particular topic.

Overall, the focus of recent literature has tended to highlight the interactions between different firms as they absorb knowledge from the outside. For instance, network analysis has become a routine method for examining alliances in aggregate. At a more micro level, firms examine their different systems and strategies for learning from the outside world.

This high degree of emphasis on external innovation may also inform the innovation literature at large. Currently, most definitions of innovation focus implicitly on internally generated innovation. For instance, another top-cited study by Baregheh et al. (2009) defines it as "the multi-stage process whereby organizations transform ideas into new/improved products, service or processes, in order to advance, compete and differentiate themselves in their marketplace." Unlike such firm-centered views of innovation, most of the topics we studied in the pharmaceutical industry had an explicit emphasis on the role of the outside world in enriching organizational innovation. With such relationships playing a central role in the industry, our understanding of the nature of innovation may be advanced by incorporating this aspect.

We found that practitioners are increasingly interested in understanding the organizational forces that influence their innovation. To further increase the diffusion of such knowledge, we recommended ways to increase the relevance of the innovation literature with practitioner needs. Primarily, as we see great value in peeking into the black box of the R\&D process, we hope to stimulate collaboration between practitioners and innovation scholars. By considering these issues that interest scientists and managers in the pharmaceutical industry, innovation scholars can help find solutions to the unique challenges facing the industry in bringing new drugs to the market.

This study mapped the landscape of innovation research on the pharmaceutical industry. As we focused on innovation issues, further analyses are needed to enumerate the specific technologies and scientific advances of concern to practitioners. For instance, recent drug discovery journals and pharmaceutical patents can be mapped to elucidate such trends. Moreover, as this analysis mainly focuses on the pharmaceutical industry, we leave out relevant adjacent areas including biotechnology, medical devices and healthcare. Nonetheless, by mapping the research landscape, this study provides the first steps towards an engaged and better-integrated literature on pharmaceutical innovation.

Acknowledgements This work was supported by the European Union's Horizon 2020 MSCA Programme under grant agreement 675899 (FRAGNET). 
Open Access This article is licensed under a Creative Commons Attribution 4.0 International License, which permits use, sharing, adaptation, distribution and reproduction in any medium or format, as long as you give appropriate credit to the original author(s) and the source, provide a link to the Creative Commons licence, and indicate if changes were made. The images or other third party material in this article are included in the article's Creative Commons licence, unless indicated otherwise in a credit line to the material. If material is not included in the article's Creative Commons licence and your intended use is not permitted by statutory regulation or exceeds the permitted use, you will need to obtain permission directly from the copyright holder. To view a copy of this licence, visit http://creativecommons.org/licenses/by/4.0/.

\section{References}

Achilladelis, B., \& Antonakis, N. (2001). The dynamics of technological innovation: The case of the pharmaceutical industry. Research Policy, 30(4), 535-588. https://doi.org/10.1016/S0048-7333(00)00093 -7 .

Ahuja, G. (2000). Collaboration networks, structural holes, and innovation: A longitudinal study. Administrative Science Quarterly. https://doi.org/10.2307/2667105.

Anand, G., Gray, J., \& Siemsen, E. (2012). Decay, shock, and renewal: Operational routines and process entropy in the pharmaceutical industry. Organization Science, 23(6), 1700-1716. https://doi. org/10.1287/orsc.1110.0709.

Arundel, A., \& Kabla, I. (1998). What percentage of innovations are patented? empirical estimates for European firms. Research Policy, 27(2), 127-141. https://doi.org/10.1016/S0048-7333(98)00033 $-\mathrm{X}$.

Athreye, S., Kale, D., \& Ramani, S. V. (2009). Experimentation with strategy and the evolution of dynamic capability in the Indian pharmaceutical sector. Industrial and Corporate Change, 18(4), 729-759. https://doi.org/10.1093/icc/dtp024.

Baregheh, A., Rowley, J., \& Sambrook, S. (2009). Towards a multidisciplinary definition of innovation. Management Decision. https://doi.org/10.1108/00251740910984578.

Barney, J. (1991). Firm resources and sustained competitive advantage. Journal of Management, 17(1), 99-120. https://doi.org/10.1177/014920639101700108.

Ben-Menahem, S. M., von Krogh, G., Erden, Z., \& Schneider, A. (2016). Coordinating knowledge creation in multidisciplinary Teams: Evidence from early-stage drug discovery. Academy of Management Journal, 59(4), 1308-1338. https://doi.org/10.5465/amj.2013.1214.

Bianchi, M., Cavaliere, A., Chiaroni, D., Frattini, F., \& Chiesa, V. (2011). Organisational modes for Open Innovation in the bio-pharmaceutical industry: An exploratory analysis. Technovation, 31(1), 22-33. https://doi.org/10.1016/j.technovation.2010.03.002.

Bierly, P., \& Chakrabarti, A. (1996). Generic knowledge strategies in the U.S. pharmaceutical industry. Strategic Management Journal, 17(S2), 123-135. https://doi.org/10.1002/smj.4250171111.

Bird, S., Klein, E., \& Loper, E. (2009). Natural Language Processing with Python. Newton: O’Reilly Media Inc. https://doi.org/10.1097/00004770-200204000-00018.

Blau, G. E., Pekny, J. F., Varma, V. A., \& Bunch, P. R. (2004). Managing a portfolio of interdependent new product candidates in the pharmaceutical industry. Journal of Product Innovation Management. https://doi.org/10.1111/j.0737-6782.2004.00075.x.

Bogart, S. (2018). SankeyMATIC: A Sankey diagram builder for everyone. https://sankeymatic.com. Accessed 15 Oct 2018.

Bogner, W. C., Thomas, H., \& Mcgee, J. (1996). A longitudinal study of the competitive positions and entry paths of European firms in the U.S. pharmaceutical market. Strategic Management Journal, 17(2), 85-107. https://doi.org/10.1002/(SICI)1097-0266(199602)17:2<85:AID-SMJ78 5>3.0.CO;2-D.

Bresman, H. (2010). External learning activities and team performance: A multimethod field study. Organization Science, 21(1), 81-96.

Bresman, H. (2013). Changing routines: A process model of vicarious group learning in pharmaceutical $\mathrm{R}$ \& D. Academy of Management Journal, 56(1), 35-61. https://doi.org/10.5465/amj.2010.0725.

Bresman, H., \& Zellmer-Bruhn, M. (2013). The structural context of team learning: Effects of organizational and team structure on internal and external learning. Organization Science, 24(4), 11201139. https://doi.org/10.1287/orsc.1120.0783.

Burt, R. S. (1992). Structural Holes: The social Structure of Competition. Cambridge, Massachussetts: Harvard University Press. https://doi.org/10.1177/0265407512465997. 
Carlsson, B., Jacobsson, S., Holmén, M., \& Rickne, A. (2002). Innovation systems: Analytical and methodological issues. Research Policy, 31(2), 233-245. https://doi.org/10.1016/S0048-7333(01)00138 -X.

Casper, S., \& Matraves, C. (2003). Institutional frameworks and innovation in the German and UK pharmaceutical industry. Research Policy, 32(10), 1865-1879. https://doi.org/10.1016/S0048 -7333(03)00082-9.

Chesbrough, H., \& Crowther, A. K. A. (2006). Beyond high tech : Early adopters of open innovation in other industries. R\&d Management, 36, 229-236.

Chesbrough, H. W. (2003). Open Innovation: The new imperative for creating and profiting from technology. Boston: Harvard Business School Press. https://doi.org/10.1111/j.1467-8691.2008.00502 .x.

Cohen, F. J. (2005). Opinion: Macro trends in pharmaceutical innovation. Nature Reviews Drug Discovery. https://doi.org/10.1038/nrd1610.

Cohen, W. M., \& Levinthal, D. A. (1990). Absorptive capacity: A new perspective on learning and innovation. Administrative Science Quarterly, 35(1), 128. https://doi.org/10.2307/2393553.

Cohen, W., Nelson, R., \& Walsh, J. (2000). Protecting Their Intellectual Assets: Appropriability Conditions and Why U.S. Manufacturing Firms Patent (or Not). Cambridge, MA. https://doi. org/10.3386/w7552

Coleman, J. S. (1988). Social capital in the creation of human-capital. American Journal of Sociology, 94, S95-S120. https://doi.org/10.1086/228943.

Cool, K., \& Dierickx, I. (1993). Rivalry, strategic groups and firm profitability. Strategic Management Journal, 14(1), 47-59. https://doi.org/10.1002/smj.4250140106.

Cool, K. O., \& Schendel, D. (1987). Strategic group formation and performance: The case of the U.S. pharmaceutical industry 1963-1982. Management Science. https://doi.org/10.1287/mnsc.33.9.1102.

Cowlrick, I., Hedner, T., Wolf, R., Olausson, M., \& Klofsten, M. (2011). Decision-making in the pharmaceutical industry: Analysis of entrepreneurial risk and attitude using uncertain information. $R$ and $D$ Management, 41(4), 321-336. https://doi.org/10.1111/j.1467-9310.2011.00649.x.

Crossan, M. M., \& Apaydin, M. (2010). A multi-dimensional framework of organizational innovation: A systematic review of the literature. Journal of Management Studies, 47(September), 1154-1191. https ://doi.org/10.1111/j.1467-6486.2009.00880.x.

D'Este, P., \& Perkmann, M. (2011). Why do academics engage with industry? The entrepreneurial university and individual motivations. Journal of Technology Transfer, 36(3), 316-339. https://doi. org/10.1007/s10961-010-9153-z.

Demirel, P., \& Mazzucato, M. (2012). Innovation and firm growth: Is R\&D worth It? Industry \& Innovation, 19(1), 45-62. https://doi.org/10.1080/13662716.2012.649057.

Dickson, M., \& Gagnon, J. (2004). Key factors in the rising cost of new drug discovery and development. Nature Reviews Drug Discovery, 3, 417-429.

Dierickx, I., \& Cool, K. (1989). Asset stock accumulation and the sustainability of competitive advantage: Reply. Management Science. https://doi.org/10.1287/mnsc.35.12.1514.

Diestre, L., \& Rajagopalan, N. (2012). Are all 'sharks' dangerous? new biotechnology ventures and partner selection in R\&D alliances. Strategic Management Journal, 33(10), 1115-1134. https://doi. org/10.1002/smj.1978.

DiMasi, J. A., Grabowski, H. G., \& Hansen, R. W. (2016). Innovation in the pharmaceutical industry: New estimates of R\&D costs. Journal of Health Economics, 47, 20-33. https://doi.org/10.1016/j.jheal eco.2016.01.012.

DiMasi, J. A., Hansen, R. W., \& Grabowski, H. G. (2003). The price of innovation: New estimates of drug development costs. Journal of Health Economics. https://doi.org/10.1016/S0167-6296(02)00126-1.

DiMasi, J. A., Hansen, R. W., Grabowski, H. G., \& Lasagna, L. (1991). Cost of innovation in the pharmaceutical industry. Journal of Health Economics, 10(2), 107-142. https://doi.org/10.1016/01676296(91)90001-4.

Dong, J. Q., \& Yang, C. (2016). Being central is a double-edged sword: Knowledge network centrality and new product development in U.S. pharmaceutical industry. Technological Forecasting and Social Change, 113, 379-385. https://doi.org/10.1016/j.techfore.2016.07.011.

Eisenhardt, K. M. (1989). Building theories from case study research. Academy of Management Review. https://doi.org/10.5465/amr.1989.4308385.

Festel, G., De Cleyn, S. H., Boutellier, R., \& Braet, J. (2011). OPTIMIZING THE R\&D PROCESS USING SPIN-OUTS : Case studies from the pharmaceutical industry. Research Technology Managemnt. https ://doi.org/10.5437/08953608X540132.

Festel, G. W. (2013). The nature of outsourced preclinical research - the example of chemical synthesis. Expert Opinion on Drug Discovery. https://doi.org/10.1517/17460441.2013.806909. 
Gambardella, A. (1980s). Competitive advantages from in-house scientific research: The US pharmaceutical industry in the 1980s. Research Policy, 21(5), 391-407. https://doi.org/10.1016/0048-7333(92)90001 $-\mathrm{K}$.

Gilsing, V., \& Nooteboom, B. (2006). Exploration and exploitation in innovation systems: The case of pharmaceutical biotechnology. Research Policy, 35(1), 1-23. https://doi.org/10.1016/j.respol.2005.06.007.

Gilsing, V., Nooteboom, B., Vanhaverbeke, W., Duysters, G., \& Van Den Oord, A. (2008). Network embeddedness and the exploration of novel technologies : Technological distance, betweenness centrality and density. Research policy, 37, 1717-1731. https://doi.org/10.1016/j.respol.2008.08.010.

Glänzel, W., \& Thijs, B. (2017). Using hybrid methods and 'core documents' for the representation of clusters and topics: The astronomy dataset. Scientometrics. https://doi.org/10.1007/s11192-017-2301-6.

Grabowski, H. (2002). Patents, innovation and access to new pharmaceuticals. Journal of International Economic Law, 5(4), 849-860.

Grabowski, H., \& Vernon, J. (1990). A new look at the returns and risks to pharmaceutical research- anddevelopment. Management Science, 36, 804-821.

Grigoriou, K., \& Rothaermel, F. T. (2017). Organizing for knowledge generation: Internal knowledge networks and the contingent effect of external knowledge sourcing. Strategic Management Journal. https ://doi.org/10.1002/smj.2489.

Guennif, S., \& Ramani, S. V. (2012). Explaining divergence in catching-up in pharma between India and Brazil using the NSI framework. Research Policy, 41(2), 430-441. https://doi.org/10.1016/j.respo 1.2011.09.005.

Gulati, R. (1998). Alliances and networks. Strategic Management Journal, 19(4), 293-317. https://doi. org/10.1002/(SICI)1097-0266(199804)19:4<293:AID-SMJ982>3.0.CO;2-M.

Guo, Y., Hu, Y., Zheng, M., \& Wang, Y. (2013). Patent indicators: A window to pharmaceutical market success. Expert Opinion on Therapeutic Patents, 23(7), 765-771.

Hagedoorn, J. (1993). Understanding the rationale of strategic technology partnering: Interorganizational modes of cooperation and sectoral differences. Strategic management journal, 14(5), 371-385. https ://doi.org/10.1002/smj.4250140505.

Hall, B. H., Jaffe, A., \& Trajtenberg, M. (2005). Market value and patent citations. RAND Journal of Economics, 36(1), 16-38.

Harhoff, D., Scherer, F. M., \& Vopel, K. (2003). Citations, family size, opposition and the value of patent rights. Research Policy, 32(8), 1343-1363. https://doi.org/10.1016/S0048-7333(02)00124-5.

Hay, M., Thomas, D. W., Craighead, J. L., Economides, C., \& Rosenthal, J. (2014). Clinical development success rates for investigational drugs. Nature Biotechnology. https://doi.org/10.1038/nbt.2786.

Heemstra, H. E., de Vrueh, R. L. A., van Weely, S., Büller, H. A., \& Leufkens, H. G. M. (2008). Orphan drug development across Europe: Bottlenecks and opportunities. Drug Discovery Today. https://doi. org/10.1016/j.drudis.2008.05.001.

Henderson, R., \& Cockburn, I. (1994). Measuring competence? exploring firm effects in pharmaceutical research. Strategic Management Journal, 15(S1), 63-84. https://doi.org/10.1002/smj.4250150906.

Hitt, M. A., Beamish, P. W., Jackson, S. E., \& Mathieu, J. E. (2007). Building theoretical and empirical bridges across levels: Multilevel research in management. Academy of Management Journal. https:// doi.org/10.5465/AMJ.2007.28166219.

Hoang, H., \& Rothaermel, F. T. (2005). The effect of general and partner-specific alliance experience on joint R\&D project Performance. Academy of Management Journal, 48(2), 332-345. https://doi. org/10.5465/amj.2005.16928417.

Hopkins, M. M., Martin, P. A., Nightingale, P., Kraft, A., \& Mahdi, S. (2007). The myth of the biotech revolution: An assessment of technological, clinical and organisational change. Research Policy, 36(4), 566-589. https://doi.org/10.1016/j.respol.2007.02.013.

Hughes, B., \& Wareham, J. (2010). Knowledge arbitrage in global pharma: A synthetic view of absorptive capacity and open innovation. $R \& D$ Management, 4O(3), 324-343. https://doi.org/10.111 1/j.1467-9310.2010.00594.x.

Hunter, J., \& Stephens, S. (2010). Is open innovation the way forward for big pharma? Nature Reviews Drug Discovery, 9(2), 87-88. https://doi.org/10.1038/nrd3099.

Jacob, W. F., \& Kwak, Y. H. (2003). In search of innovative techniques to evaluate pharmaceutical R\&D projects. Technovation, 23(4), 291-296. https://doi.org/10.1016/S0166-4972(01)00116-X.

Kale, D., \& Little, S. (2007). From imitation to innovation: The evolution of R\&fD capabilities and learning processes in the Indian pharmaceutical industry. Technology Analysis \& Strategic Management, 19(5), 589-609. https://doi.org/10.1080/09537320701521317.

Kapoor, R., \& Klueter, T. (2015). Decoding the adaptability-rigidity puzzle: Evidence from pharmaceutical incumbents' pursuit of gene therapy and monoclonal antibodies. Academy of Management Journal, 58(4), 1180-1207. https://doi.org/10.5465/amj.2013.0430. 
Kneller, R. (2010). The importance of new companies for drug discovery: Origins of a decade of new drugs. Nature Reviews Drug Discovery, 9(11), 867-882. https://doi.org/10.1038/nrd3251.

Kuemmerle, W. (1999). Foreign direct investment in industrial research in the pharmaceutical and electronics industries - results from a survey of multinational firms. Research Policy, 28(2-3), 179-193. https ://doi.org/10.1016/S0048-7333(98)00110-3.

Lane, P. J., \& Lubatkin, M. (1998). Relative absorptive capacity and interorganizational learning. Strategic Management Journal, 19(5), 461-477. https://doi.org/10.1002/(SICI)1097-0266(19980 5) 19:5<461:AID-SMJ953>3.3.CO;2-C.

Laursen, K., \& Salter, A. (2006). Open for innovation: The role of openness in explaining innovation performance among U.K. manufacturing firms. Strategic Management Journal, 27(2), 131-150. https://doi. org/10.1002/smj.507.

Lemus, J., \& Marshall, G. (2018). When the clock starts ticking: Measuring strategic responses to TRIPS's patent term change. Research Policy. https://doi.org/10.1016/j.respol.2018.02.008.

Liu, C. C., Srivastava, S. B., \& Stuart, T. E. (2015). An intraorganizational ecology of individual attainment. Organization Science. https://doi.org/10.1287/orsc.2015.1020.

Liu, Q., Gupta, S., Venkataraman, S., \& Liu, H. (2016). An empirical model of drug detailing: Dynamic competition and policy implications. Management Science, 62(8), 2321-2340. https://doi. org/10.1287/mnsc.2015.2239.

Lundvall, B.-A. (1993). National systems of innovation: Towards a theory of innovation and interactive learning. Prometheus. https://doi.org/10.1080/08109029308629360.

Malerba, F., \& Orsenigo, L. (2015). The evolution of the pharmaceutical industry. Business History, 57(5), 664-687. https://doi.org/10.1080/00076791.2014.975119.

Mansfield, E. (1986). Patents and innovation: An empirical study. Management Science, 32(2), $173-181$. https://doi.org/10.1287/mnsc.32.2.173.

March, J. G. (1991). Exploration and exploitation in organizational learning. Organization Science, 2(1), 71-87. https://doi.org/10.1287/orsc.2.1.71.

Mason, R., \& Drakeman, D. L. (2014). Comment on "fishing for sharks: Partner selection in biopharmaceutical R\&D alliances" by diestre and rajagopalan. Strategic Management Journal, 35(10), 1564-1565. https://doi.org/10.1002/smj.2177.

McGee, J., \& Thomas, H. (1986). Strategic groups: Theory, research and taxonomy. Strategic Management Journal. https://doi.org/10.1002/smj.4250070204.

McMillan, G. S., Narin, F., \& Deeds, D. L. (2000). An analysis of the critical role of public science in innovation: The case of biotechnology. Research Policy. https://doi.org/10.1016/S0048 -7333(99)00030-X.

Mittra, J., Tait, J., \& Wield, D. (2011). From maturity to value-added innovation: Lessons from the pharmaceutical and agro-biotechnology industries. Trends in Biotechnology. https://doi.org/10.1016/j. tibtech.2010.11.004.

Mizik, N., \& Jacobson, R. (2004). Are physicians "easy marks"? quantifying the effects of detailing and sampling on new prescriptions. Management Science, 50(12), 1704-1715. https://doi.org/10.1287/ mnsc. 1040.0281 .

Moors, E. H. M., Cohen, A. F., \& Schellekens, H. (2014). Towards a sustainable system of drug development. Drug Discovery Today, 19(11), 1711-1720. https://doi.org/10.1016/j.drudis.2014.03.004.

Moran, P. (2005). Structural vs relational embeddedness: Social capital and managerial performance. Strategic Management Journal, 26(12), 1129-1151. https://doi.org/10.1002/smj.486.

Natsukawa, T., Gemba, K., \& Ishida, S. (2013). The timing of interorganisational collaborations in an emerging biopharmaceutical field: Evidence from Japan in comparison to the remaining RNAi field. Technology Analysis and Strategic Management, 25(5), 583-597. https://doi. org/10.1080/09537325.2013.785509.

Nelson, R. R. (1993). National Innovation Systems: A Comparative Analysis. Oxford: Oxford University Press.

Nelson, R. R., \& Winter, S. G. (1982). An evolutionary theory of economic change. Cambridge MA Belknap. https://doi.org/10.2307/2232409.

Orsenigo, L., Pammolli, F., \& Riccaboni, M. (2001). Technological change and network dynamics: Lessons from the pharmaceutical industry. Research Policy, 30(3), 485-508. https://doi.org/10.1016/ S0048-7333(00)00094-9.

Pammolli, F., Magazzini, L., \& Riccaboni, M. (2011). The productivity crisis in pharmaceutical R\&D. Nature Reviews Drug Discovery, 10(6), 428-438. https://doi.org/10.1038/nrd3405.

Paruchuri, S. (2010). Intraorganizational networks, interorganizational networks, and the impact of central inventors: A longitudinal study of pharmaceutical firms. Organization Science, 21(1), 63-80. https://doi.org/10.1287/orsc.1080.0414. 
Patel, M. N., Halling-Brown, M. D., Tym, J. E., Workman, P., \& Al-Lazikani, B. (2013). Objective assessment of cancer genes for drug discovery. Nature Reviews Drug Discovery, 12(1), 35-50.

Patterson, W., \& Ambrosini, V. (2015). Configuring absorptive capacity as a key process for research intensive firms. Technovation, 36, 77-89. https://doi.org/10.1016/j.technovation.2014.10.003.

Paul, S. M., Mytelka, D. S., Dunwiddie, C. T., Persinger, C. C., Munos, B. H., Lindborg, S. R., et al. (2010). How to improve R\&D productivity: the pharmaceutical industry's grand challenge. Nature Reviews Drug Discovery, 9(3), 203-214. https://doi.org/10.1038/nrd3078.

Pisano, G. P. (1994). Knowledge, integration, and the locus of learning: An empirical analysis of process development. Strategic Management Journal, 15(S1), 85-100. https://doi.org/10.1002/smj.42501 50907.

Porter, M. E. (1980). Competitive strategy. New York: Free Press.

Powell, W. W. (1998). Learning from Collaboration: Knowledge and Networks in the Biotechnology and Pharmaceutical Industries. California Management Review, 40(3), 228-240. https://doi. org/10.2307/41165952.

Powell, W. W., Koput, K. W., \& Smith-Doerr, L. (1996). Interorganizational Collaboration and the Locus of Innovation: Networks of Learning in Biotechnology. Administrative Science Quarterly, 41(1), 116. https://doi.org/10.2307/2393988.

Powell, W. W., White, D. R., Koput, K. W., \& Owen-Smith, J. (2005). Network dynamics and field evolution: The growth of interorganizational collaboration in the life sciences. American Journal of Sociology, 110(4), 1132-1205. https://doi.org/10.1086/421508.

Rafols, I., Hopkins, M. M., Hoekman, J., Siepel, J., O’Hare, A., Perianes-Rodríguez, A., et al. (2014). Big Pharma, little science? Technological Forecasting and Social Change, 81, 22-38. https://doi. org/10.1016/j.techfore.2012.06.007.

Ramos, J. (2003). Using TF-IDF to Determine Word Relevance in Document Queries. In: Proceedings of the first instructional conference on machine learning. 10.1.1.121.1424.

Rothaermel, F. T. (2001). Incumbent's advantage through exploiting complementary assets via interfirm cooperation. Strategic Management Journal, 22(6-7), 687-699. https://doi.org/10.1002/smj.180.

Rothaermel, F. T., \& Boeker, W. (2008). Old technology meets new technology: Complementarities, similarities, and alliance formation. Strategic Management Journal, 29(1), 47-77. https://doi.org/10.1002/ smj.634.

Rothaermel, F. T., \& Deeds, D. L. (2004). Exploration and exploitation alliances in biotechnology: A system of new product development. Strategic Management Journal, 25(3), 201-221. https://doi. org/10.1002/smj.376.

Rzakhanov, Z. (2008). Regulatory policy, value of knowledge assets and innovation strategy: The case of the orphan drug act. Research Policy, 37, 673-689. https://doi.org/10.1016/j.respol.2007.12.009.

Santos, F. M. (2003). The coevolution of firms and their knowledge environment: Insights from the pharmaceutical industry. Technological Forecasting and Social Change, 70(7), 687-715. https://doi. org/10.1016/S0040-1625(03)00031-3.

Saotome, C., Nakaya, Y., \& Abe, S. (2016). Patent production is a prerequisite for successful exit of a biopharmaceutical company. Drug Discovery Today. https://doi.org/10.1016/j.drudis.2015.12.005.

Scannell, J. W., Blanckley, A., Boldon, H., \& Warrington, B. (2012). Diagnosing the decline in pharmaceutical R\&D efficiency. Nature Reviews Drug Discovery, 11(3), 191-200. https://doi.org/10.1038/nrd36 81 .

Schuhmacher, A., Gassmann, O., \& Hinder, M. (2016). Changing R\&D models in research-based pharmaceutical companies. Journal of Translational Medicine. https://doi.org/10.1186/s12967-016-0838-4.

Stryker, J. B., Santoro, M. D., \& Farris, G. F. (2012). Creating collaboration opportunity: Designing the physical workplace to promote high-tech team communication. IEEE Transactions on Engineering Management, 59(4), 609-620. https://doi.org/10.1109/TEM.2011.2170995.

Stuart, T. E., Ozdemir, S. Z., \& Ding, W. W. (2007). Vertical alliance networks: The case of university-biotechnology-pharmaceutical alliance chains. Research Policy, 36(4), 477-498. https://doi. org/10.1016/j.respol.2007.02.016.

Tang, C. (2016). Accessed external knowledge, centrality of intra-team knowledge networks, and R\&D employee creativity. $R \& D$ Management, 46(S3), 992-1005. https://doi.org/10.1111/radm.12160.

Thomke, S., \& Kuemmerle, W. (2002). Asset accumulation, interdependence and technological change: Evidence from pharmaceutical drug discovery. Strategic Management Journal, 23(7), 619-635. https ://doi.org/10.1002/smj.242.

Thongpapanl, N. (2012). The changing landscape of technology and innovation management: An updated ranking of journals in the field. Technovation. https://doi.org/10.1016/j.technovation.2012.01.001. 
Tierney, R., Hermina, W., \& Walsh, S. (2013). The pharmaceutical technology landscape: A new form of technology roadmapping. Technological Forecasting and Social Change, 80(2), 194-211. https://doi. org/10.1016/j.techfore.2012.05.002.

Trajtenberg, M. (1990). A penny for your quotes: Patent citations and the value of innovations. The RAND Journal of Economics. https://doi.org/10.2307/2555502.

Tralau-Stewart, C. J., Wyatt, C. A., Kleyn, D. E., \& Ayad, A. (2009). Drug discovery: New models for industry-academic partnerships. Drug Discovery Today, 14(1-2), 95-101. https://doi.org/10.1016/j. drudis.2008.10.003.

Trott, P., \& Hartmann, D. (2009). Why "open innovation” is old wine in new bottles. International Journal of Innovation Management, 13(04), 715-736. https://doi.org/10.1142/S1363919609002509.

Vakili, K., \& McGahan, A. M. (2016). Health care's grand challenge: Stimulating basic science on diseases that primarily afflict the poor. Academy of Management Journal., 59, 1917-1939. https://doi. org/10.5465/amj.2015.0641.

van de Vrande, V. (2013). Balancing your technology-sourcing portfolio: How sourcing mode diversity enhances innovative performance. Strategic Management Journal, 34(5), 610-621. https://doi. org/10.1002/smj.2031.

van Eck, N. J., \& Waltman, L. (2010). Software survey: VOSviewer, a computer program for bibliometric mapping. Scientometrics, 84(2), 523-538.

van Merkerk, R. O., \& Robinson, D. K. R. (2006). Characterizing the emergence of a technological field: Expectations, agendas and networks in Lab-on-a-chip technologies. Technology Analysis \& Strategic Management, 18(3-4), 411-428. https://doi.org/10.1080/09537320600777184.

Vinet, L., \& Zhedanov, A. (2011). A 'missing' family of classical orthogonal polynomials. Journal of Physics A: Mathematical and Theoretical, 44(8), 085201. https://doi.org/10.1088/1751-8113/44/8/085201.

Waltman, L., van Eck, N. J., \& Noyons, E. C. M. (2010). A unified approach to mapping and clustering of bibliometric networks. Journal of Informetrics. https://doi.org/10.1016/j.joi.2010.07.002.

Zucker, L. G., \& Darby, M. R. (1997). Present at the biotechnological revolution: Transformation of technological identity for a large incumbent pharmaceutical firm. Research Policy, 26(4-5), 429-446. 